\title{
COLLISIONAL IONIZATION EQUILIBRIUM FOR OPTICALLY THIN PLASMAS. I. UPDATED RECOMBINATION RATE COEFFICIENTS FOR BARE THROUGH SODIUM-LIKE IONS
}

\author{
P. Bryans, ${ }^{1}$ N. R. Badnell, ${ }^{2}$ T. W. Gorczyca, ${ }^{3}$ J. M. Laming, ${ }^{4}$ W. Mitthumsiri, ${ }^{1}$ and D. W. SAvin ${ }^{1}$ \\ Received 2006 April 17; accepted 2006 June 26
}

\begin{abstract}
Reliably interpreting spectra from electron-ionized cosmic plasmas requires accurate ionization balance calculations for the plasma in question. However, much of the atomic data needed for these calculations have not been generated using modern theoretical methods and are often highly suspect. This translates directly into the reliability of the collisional ionization equilibrium (CIE) calculations. We make use of state-of-the-art calculations of dielectronic recombination (DR) rate coefficients for the hydrogenic through Na-like ions of all elements from He up to and including $\mathrm{Zn}$. Where measurements exist, these published theoretical DR data agree with recent laboratory work to within typically $35 \%$ or better at the temperatures relevant for CIE. We also make use of state-of-the-art radiative recombination (RR) rate coefficient calculations for the bare through Na-like ions of all elements from $\mathrm{H}$ through to $\mathrm{Zn}$. Here we present improved CIE calculations for temperatures from $10^{4}$ to $10^{9} \mathrm{~K}$ using our data and the recommended electron impact ionization data of Mazzotta et al. for elements up to and including Ni and Mazzotta for $\mathrm{Cu}$ and $\mathrm{Zn}$. DR and RR data for ionization stages that have not been updated are also taken from these two additional sources. We compare our calculated fractional ionic abundances using these data with those presented by Mazzotta et al. for all elements from $\mathrm{H}$ to Ni. The differences in peak fractional abundance are up to $60 \%$. We also compare with the fractional ionic abundances for $\mathrm{Mg}, \mathrm{Si}, \mathrm{S}, \mathrm{Ar}, \mathrm{Ca}, \mathrm{Fe}$, and $\mathrm{Ni}$ derived from the modern $\mathrm{DR}$ calculations of $\mathrm{Gu}$ for the $\mathrm{H}$-like through Na-like ions, and the RR calculations of Gu for the bare through F-like ions. These results are in better agreement with our work, with differences in peak fractional abundance of less than $10 \%$.
\end{abstract}

Subject headings: atomic data — atomic processes — plasmas

Online material: extended figure sets, machine-readable tables

\section{INTRODUCTION}

Electron ionized plasmas (also called collisionally ionized plasmas) are formed in a diverse variety of objects in the universe. These range from stellar coronae and supernova remnants through to the interstellar medium and gas in galaxies or in clusters of galaxies. The physical properties of these sources can be determined using spectral observations coupled with theoretical models. This allows one to infer electron and ion temperatures, densities, emission measure distributions, and ion and elemental abundances. However, reliably determining these properties requires accurate fractional abundance calculations for the different ionization stages of the various elements in the plasma (i.e., the ionization balance of the gas).

Since many of the observed sources are not in local thermodynamic equilibrium, in order to determine the ionization balance of the plasma one needs to know the rate coefficients for all the relevant recombination and ionization processes. Often, the observed systems are optically thin, low-density, dust-free, and in steady state or quasi-steady state. Under these conditions the effects of any radiation field can be ignored, density effects are insignificant, three-body collisions are unimportant, and the ionization balance of the gas is time-independent. This is commonly called collisional ionization equilibrium (CIE) or sometimes coronal equilibrium.

\footnotetext{
${ }^{1}$ Columbia Astrophysics Laboratory, Columbia University, New York, NY 10027.

${ }_{2}$ Department of Physics, University of Strathclyde, Glasgow, G4 0NG, UK.

3 Department of Physics, Western Michigan University, Kalamazoo, MI 49008

4 E. O. Hulburt Center for Space Research, US Naval Research Laboratory, Code 7674L, Washington, DC 20375.
}

Because CIE occurs in a wide range of cosmic sources, accurate calculations have long been an issue of concern. One of the continuing challenges of theoretical and experimental atomic physics is to provide reliable data for all the relevant collision processes. In CIE, recombination is due to dielectronic recombination (DR) and radiative recombination (RR). At the temperature of peak formation in CIE, DR dominates over RR for most ions. Ionization is a result of electron impact ionization (EII). At temperatures low enough for both atoms and ions to exist, charge transfer (CT) can be both an important recombination and ionization process. Considering all the ions and levels that need to be taken into account, it is clear that vast quantities of data are needed. Generating them to the accuracy required pushes theoretical and experimental methods to the edge of what is currently achievable and often beyond. For this reason progress has been slow.

Over the years a number of different groups have evaluated the available atomic data and produced CIE calculations. Some of the most commonly cited results are those of Shull \& van Steenberg (1982), Arnaud \& Rothenflug (1985), Landi \& Monsignori Fossi (1991), Arnaud \& Raymond (1992), and Mazzotta et al. (1998). Masai (1997) investigated the astrophysical implications for several different CIE models on the fractional abundance of Fe. More recently, Gu (2003b) carried out CIE calculations using his DR and RR rate coefficients and compared them with the CIE results of Mazzotta et al. (1998) for Mg, Si, S, Ar, Ca, Fe, and Ni. Our efforts here are just another step in what promises to be a long line of studies aimed at providing the astrophysics community with the most reliable CIE calculations currently possible.

The work here is motivated in specific by recent advances in our understanding of DR. With the development in the late 1980s of electron beam ion traps (EBITs) and heavy-ion storage rings 
TABLE 1

Published AUtostructure DR Rate Coefficients

\begin{tabular}{|c|c|}
\hline Isoelectronic Sequence & Publication \\
\hline H-like ............................ & Badnell (2006c) \\
\hline 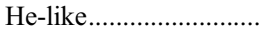 & Bautista \& Badnell (2006) \\
\hline Li-like............................... & Colgan et al. (2004) \\
\hline 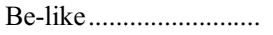 & Colgan et al. (2003) \\
\hline B-like............................... & Altun et al. (2004) \\
\hline C-like............................... & Zatsarinny et al. (2004a) \\
\hline 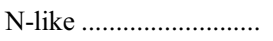 & Mitnik \& Badnell (2004) \\
\hline 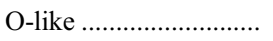 & Zatsarinny et al. (2003) \\
\hline 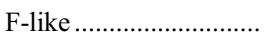 & Zatsarinny et al. (2006) \\
\hline 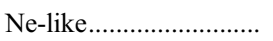 & Zatsarinny et al. (2004b); J. Fu et al. (in prep.) \\
\hline Na-like........................... & Altun et al. (2006) \\
\hline
\end{tabular}

NoтEs.-Data have been published for all elements from He through $\mathrm{Zn}$. These data were calculated using the techniques described in Badnell et al. (2003). The complete data set is provided via the weblink of Badnell (2006a).

combined with electron coolers, it has become possible to carry out detailed DR measurements for a wide range of systems (Müller \& Wolf 1997; Schippers 1999; Beiersdorfer 2003). These results, in turn, have been used to test various state-of-the-art theoretical methods for calculating DR. Using these benchmarked methods, over the last few years a number of groups have systematically calculated DR for K- and L-shell ions and M-shell Na-like ions of various elements (Gu 2003b, 2004; Badnell et al. 2003; Badnell 2006a; see also Table 1). These groups have also recently calculated state-of-the-art RR rate coefficients for K- and L-shell ions and $\mathrm{M}$-shell Na-like ions for a number of elements $(\mathrm{Gu}$ 2003a; Badnell 2006b, 2006d).

Using these new DR and RR results we have computed the CIE fraction abundances for the various ionization stages of all elements from $\mathrm{H}$ up to and including $\mathrm{Zn}$. We present results for plasma temperatures from $10^{4}$ to $10^{9} \mathrm{~K}$. The rest of this paper is organized as follows: In $\S 2$ we review recent developments in our understanding of DR. Section 3 discusses recent improvements in the theoretical calculation of RR rate coefficients. In $\S 4$ we discuss recent published unified DR $+\mathrm{RR}$ rate coefficients. Section 5 briefly discusses the status of the EII rate coefficients. Updating these data will be the subject of a future paper. In $\S 6$ we give a short overview of the importance of CT in electron ionized plasmas. We will incorporate $\mathrm{CT}$ into future calculations. Section 7 outlines the equations relating ionization fractions to the rate coefficients and describes how we solve these equations. In $\S 8$ we present our new CIE calculations and compare these results to the ionization balance results of Mazzotta et al. (1998) and to CIE calculations based on the data of $\mathrm{Gu}(2003 \mathrm{~b}, 2003 \mathrm{a}$, 2004). Section 9 discusses the results of our calculations and, in particular, how they differ from previous studies. Concluding remarks are given in $\S 10$.

\section{DIELECTRONIC RECOMBINATION (DR)}

Dielectronic recombination (DR) is a two-step recombination process that begins when an electron collisionally excites a core electron of an ion and is simultaneously captured. The core electron excitation can be labeled $n l_{j} \rightarrow n^{\prime} l_{l^{\prime}}^{\prime}$, where $n$ is the principal quantum number, $l$ is the orbital angular momentum, and $j$ is the total angular momentum. We label the change in principal quantum number as $\Delta n=n^{\prime}-n$. The energy of this intermediate system lies in the continuum and the complex may autoionize. The DR process is complete when the system emits a photon, reducing the total energy of the recombined system to below its ionization threshold. Conservation of energy requires that for DR to go for- ward $E_{k}=\Delta E-E_{b}$. Here $E_{k}$ is the kinetic energy of the incident electron, $\Delta E$ the excitation energy of the initially bound electron in the presence of the captured electron, and $E_{b}$ the binding energy released when the incident electron is captured onto the excited ion. Because $\Delta E$ and $E_{b}$ are quantized, DR is a resonant process.

Badnell et al. (2003) have calculated the DR rate coefficients using the semirelativistic AUTOSTRUCTURE code (Badnell 1986 ) for the H- through Na-like isoelectronic sequences of all elements from He through to $\mathrm{Zn}$ (see Table 1; we use the convention here of identifying the recombination process by the initial charge state of the ion). These new DR data have been collected together and are available online (Badnell 2006a). In addition, some of the original data have been refitted so as to extend the validity of the fits to lower temperatures. Gu (2003b) has calculated DR rate coefficients using the relativistic FAC code for the $\mathrm{H}$ - through Ne-like isoelectronic sequences of $\mathrm{Mg}, \mathrm{Si}, \mathrm{S}, \mathrm{Ar}, \mathrm{Ca}$, $\mathrm{Fe}$, and $\mathrm{Ni}$ and for the Na-like sequence for $\mathrm{Mg}$ through $\mathrm{Zn}(\mathrm{Gu}$ 2004). Both the calculations of Gu (2003b, 2004) and Badnell et al. (2003) were performed in the independent processes, isolated resonance approximation (Seaton \& Storey 1976), using a distorted-wave representation. For the ions considered here, the low collision energies of the important DR resonances means that a fully relativistic treatment is not necessary. The methodology of the AUTOSTRUCTURE and FAC calculations is basically the same, with the differences coming mostly from the atomic structure.

In the temperature range where the fractional CIE abundance of an ion is greater than 0.01 (what we call here the CIE formation zone), we find the DR data of Badnell (2006a) and Gu (2003b, 2004) to be in good agreement except for Ne-like ions. The agreement is to within better than $\sim 35 \%$ for Li-like Mg and $\sim 25 \%$ for other $\mathrm{Mg}$ ions, $\sim 25 \%$ for $\mathrm{Si}$ and $\mathrm{S}$ ions, $\sim 20 \%$ for $\mathrm{Ar}$ and $\mathrm{Ca}$ ions, and $\sim 15 \%$ for $\mathrm{Fe}$ and $\mathrm{Ni}$ ions.

For Ne-like ions the agreement is significantly poorer $(\mathrm{Gu}$ 2003b; Zatsarinny et al. 2004b; J. Fu et al. 2007, in preparation). Differences are seen of up to $\sim 140 \%$ for $\mathrm{Mg}^{2+}$ and $\mathrm{Si}^{4+}, \sim 55 \%$ for $\mathrm{S}^{6+}, \sim 60 \%$ for $\mathrm{Ar}^{8+}, \sim 35 \%$ for $\mathrm{Ca}^{10+}$, and $\sim 15 \%$ for $\mathrm{Fe}^{16+}$ and $\mathrm{Ni}^{1{ }^{18+}}$. However, these differences occur at temperatures below the peak in the DR rate coefficient, where recombination is dominated by RR and DR is unimportant. A comparison of peak DR rate coefficients reveals differences of $\sim 30 \%$ for $\mathrm{Mg}^{2+}$ and $\sim 10 \%$ for the remaining six ions calculated by $\mathrm{Gu}$ (2003b).

In CIE, for K-shell ions of the elements considered here DR proceeds via $\Delta n \geq 1$ core excitations independent of the atomic number $Z$ of the system. These have been well studied experimentally using EBITs and storage rings. State-of-the-art DR theory such as that of Badnell (2006a) and $\mathrm{Gu}$ (2003b) reproduce the experimental results with agreement on the order of $\sim 20 \%$ (Müller 1995; Savin \& Laming 2002).

For Li- to Na-like L- and M-shell ions of the elements considered here, at low $Z$ DR proceeds primarily via $\Delta n=0$ core excitations (except for Ne-like ions, which have no $\Delta n=0$ channels). For intermediate $Z$, DR proceeds via a mix of $\Delta n=0$ and 1 core excitation. At higher $Z$, DR proceeds primarily via $\Delta n=1$ excitations. DR for all these ions is not as well understood as for K-shell systems.

Storage ring measurements of the $\mathrm{L}$ shell have been reviewed most recently by Schippers (1999) and Savin et al. (2006). Experimental work on M-shell Na-like systems is given in Linkemann et al. (1995), Müller (1999), and Fogle et al. (2003). For $\Delta n=0$ $\mathrm{DR}$, quite a number of laboratory measurements exist for $\mathrm{Li}$ - and Be-like ions. Significantly less work exists for B-, C-, N-, O-, $\mathrm{F}-$, and Na-like ions. For $\mathrm{C}-, \mathrm{N}-$, and O-like ions, storage ring measurements exist for only a single ion in each sequence. For 
TABLE 2

Sources of Data for the AUtostructure-based CiE Calculations

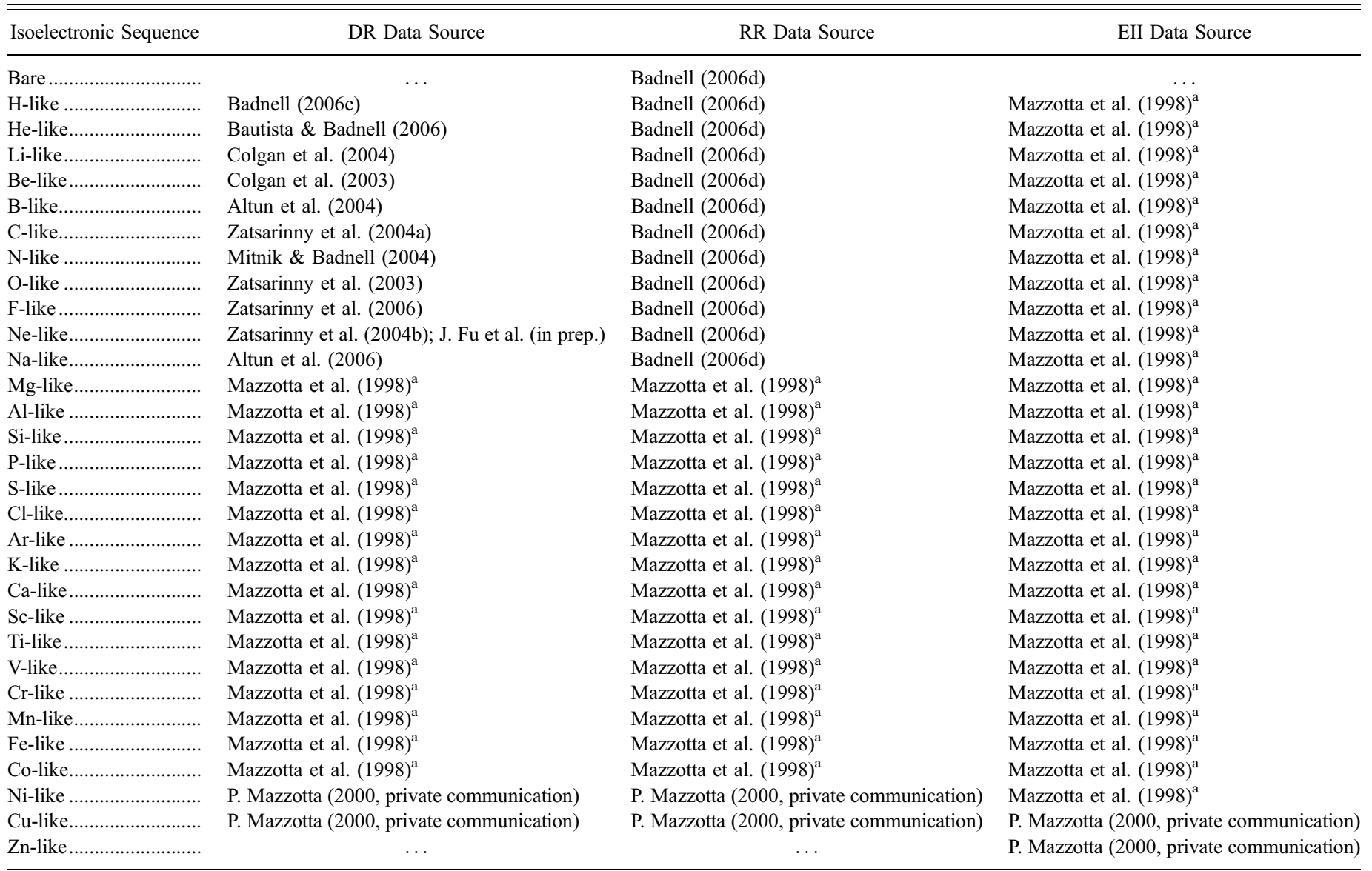

Notes.-These are the data used to produce the CIE results given in Fig. Set 2 and Table 4. The AUTOSTRUCTURE DR data (Badnell 2006a) and RR data (Badnell 2006b) are also available online.

${ }^{\text {a }}$ The data from Mazzotta et al. (1998) is replaced by P. Mazzotta (2000, private communication) for the elements $\mathrm{Cu}$ and $\mathrm{Zn}$.

the B-, F-, and Na-like ions, they exist for only two ions in each sequence. The situation for $\Delta n=1 \mathrm{DR}$ is even spottier. Results have been published for some Li-, Be-, O-, F-, and Na-like ions. For the O-, F-, and Na-like ions, measurements exist for only one ion in each sequence. We are unaware of any published $\Delta n=1$ measurements for ions in the B-, C-, N-, or Ne-like isoelectronic sequences. Clearly, additional benchmark laboratory work is called for.

To summarize the comparison between state-of-the-art theory and experiment for the above L- and M-shell isoelectronic sequences, for $\Delta n=0 \mathrm{DR}$ at collision energies $\gtrsim 1-3 \mathrm{eV}$ and for $\Delta n=1 \mathrm{DR}$, agreement with the stronger DR resonances is typically better than $35 \%$. Problems arise, however, with $\Delta n=0$ DR for collision energies below $\lesssim 1-3 \mathrm{eV}$, where modern theory has difficulty reliably calculating DR resonance energies. These differences translate directly into an uncertainty in the DR rate coefficient for $T_{e} \lesssim 10,000-35,000 \mathrm{~K}$. There is no clear $Z$ dependence scaling for this energy or temperature limit. For example, Be-like $\mathrm{C}^{2+}$ (Fogle et al. 2005), B-like $\mathrm{Ar}^{13+}$ (DeWitt et al. 1996), and C-like $\mathrm{Fe}^{20+}$ (Savin et al. 2003) all show discrepancies between theory and experiment for energies below $\sim 3 \mathrm{eV}$. On the other hand, O-like $\mathrm{Fe}^{18+}, \mathrm{F}$-like $\mathrm{Fe}^{17+}$, and $\mathrm{Na}$-like $\mathrm{Ni}^{17+}$ all show good agreement between theoretical and experimental resonance energies down to $0.1 \mathrm{eV}$ (Savin et al. 1997, 1999; Fogle et al. 2003). The $1-3 \mathrm{eV}$ limit given above is more a function of the Rydberg level into which the incident electron is captured. For high levels, correlation effects are unimportant and theory can reliably calculate the DR resonance energies and strengths and hence reliable DR rate coefficients. But for low levels, this is not the case.

The reliability of DR rate coefficients for $T_{e} \lesssim 35,000 \mathrm{~K}$ must be evaluated on a case-by-case basis. Theoretical calculations can be used as an evaluation guide by determining which Rydberg levels are important below $3 \mathrm{eV}$. But laboratory benchmark measurements are also needed. Fortunately in CIE, only singly and doubly charged ions form in significant abundances at these temperatures ( based on our fractional abundance calculations below). So any theoretical uncertainties will affect mostly DR data only for these ions. In a future work we will investigate theoretically for which ions this is most likely to be an issue.

Below 25,000 K, CT with atomic $\mathrm{H}$ is also important, as is discussed in $\S 6$. Since we do not include CT in our CIE calculations here, we have also chosen not to include what little experimentally derived DR data for singly and doubly charged ions exist. Both CT and any published experimental DR results will be included in future work.

For ionization stages not included in the state-of-the-art calculations of Badnell (2006a) and Gu (2003b, 2004), we use the DR rate coefficients recommended by Mazzotta et al. (1998) for elements up to and including $\mathrm{Ni}$ and those recommended by P. Mazzotta (2000, private communication) for $\mathrm{Cu}$ and $\mathrm{Zn}$. These older data come from a variety of sources and are typically less 
TABLE 3

Sources of Data Used in the FAC-based Cie Calculations

\begin{tabular}{|c|c|c|c|}
\hline Isoelectronic Sequence & DR Data Source & RR Data Source & EII Data Source \\
\hline Bare & & $\mathrm{Gu}(2003 \mathrm{a})$ & \\
\hline H-like & $\mathrm{Gu}(2003 \mathrm{~b})$ & $\mathrm{Gu}(2003 \mathrm{a})$ & Mazzotta et al. (1998) \\
\hline 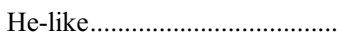 & $\mathrm{Gu}(2003 \mathrm{~b})$ & $\mathrm{Gu}(2003 \mathrm{a})$ & Mazzotta et al. (1998) \\
\hline 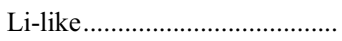 & $\mathrm{Gu}(2003 \mathrm{~b})$ & Gu (2003a) & Mazzotta et al. (1998) \\
\hline 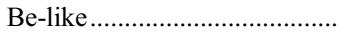 & $\mathrm{Gu}(2003 \mathrm{~b})$ & Gu (2003a) & Mazzotta et al. (1998) \\
\hline B-like............ & $\mathrm{Gu}(2003 \mathrm{~b})$ & Gu (2003a) & Mazzotta et al. (1998) \\
\hline C-like......... & $\mathrm{Gu}(2003 \mathrm{~b})$ & Gu (2003a) & Mazzotta et al. (1998) \\
\hline N-like & $\mathrm{Gu}(2003 \mathrm{~b})$ & $\mathrm{Gu}(2003 \mathrm{a})$ & Mazzotta et al. (1998) \\
\hline 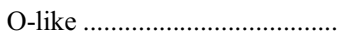 & $\mathrm{Gu}(2003 \mathrm{~b})$ & Gu (2003a) & Mazzotta et al. (1998) \\
\hline 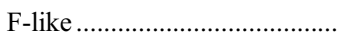 & $\mathrm{Gu}(2003 \mathrm{~b})$ & $\mathrm{Gu}(2003 \mathrm{a})$ & Mazzotta et al. (1998) \\
\hline 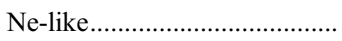 & $\mathrm{Gu}(2003 \mathrm{~b})$ & Mazzotta et al. (1998) & Mazzotta et al. (1998) \\
\hline 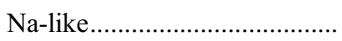 & $\mathrm{Gu}(2004)$ & Mazzotta et al. (1998) & Mazzotta et al. (1998) \\
\hline 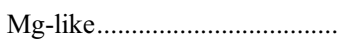 & Mazzotta et al. (1998) & Mazzotta et al. (1998) & Mazzotta et al. (1998) \\
\hline Al-like ........................ & Mazzotta et al. (1998) & Mazzotta et al. (1998) & Mazzotta et al. (1998) \\
\hline Si-like & Mazzotta et al. (1998) & Mazzotta et al. (1998) & Mazzotta et al. (1998) \\
\hline 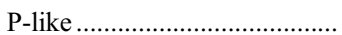 & Mazzotta et al. (1998) & Mazzotta et al. (1998) & Mazzotta et al. (1998) \\
\hline 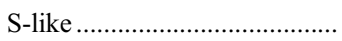 & Mazzotta et al. (1998) & Mazzotta et al. (1998) & Mazzotta et al. (1998) \\
\hline 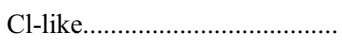 & Mazzotta et al. (1998) & Mazzotta et al. (1998) & Mazzotta et al. (1998) \\
\hline 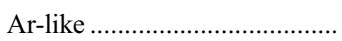 & Mazzotta et al. (1998) & Mazzotta et al. (1998) & Mazzotta et al. (1998) \\
\hline K-like ......... & Mazzotta et al. (1998) & Mazzotta et al. (1998) & Mazzotta et al. (1998) \\
\hline 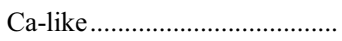 & Mazzotta et al. (1998) & Mazzotta et al. (1998) & Mazzotta et al. (1998) \\
\hline 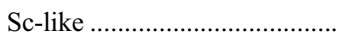 & Mazzotta et al. (1998) & Mazzotta et al. (1998) & Mazzotta et al. (1998) \\
\hline 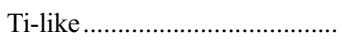 & Mazzotta et al. (1998) & Mazzotta et al. (1998) & Mazzotta et al. (1998) \\
\hline 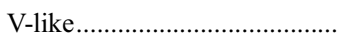 & Mazzotta et al. (1998) & Mazzotta et al. (1998) & Mazzotta et al. (1998) \\
\hline 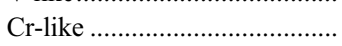 & Mazzotta et al. (1998) & Mazzotta et al. (1998) & Mazzotta et al. (1998) \\
\hline 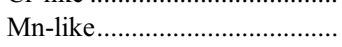 & Mazzotta et al. (1998) & Mazzotta et al. (1998) & Mazzotta et al. (1998) \\
\hline 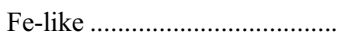 & Mazzotta et al. (1998) & Mazzotta et al. (1998) & Mazzotta et al. (1998) \\
\hline 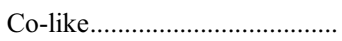 & Mazzotta et al. (1998) & Mazzotta et al. (1998) & Mazzotta et al. (1998) \\
\hline Ni-like & $\ldots$ & & Mazzotta et al. (1998) \\
\hline
\end{tabular}

Note.-These are the data used to produce the CIE results given in Fig. Set 3 and Table 5.

reliable than more modern results. The sources of DR data used in our CIE calculations are listed in Tables 2 and 3.

\section{RADIATIVE RECOMBINATION (RR)}

Radiative recombination ( $R R$ ) is a one-step recombination process that occurs when a free electron is captured by an ion. Energy and momentum are conserved in the process by the simultaneous emission of a photon. Quantum mechanically, DR and RR are indistinguishable processes that interfere with each other. Pindzola et al. (1992) have shown that this interference is a very small effect and can safely be neglected in most cases. This gives the independent processes approximation whereby DR and $\mathrm{RR}$ can be considered separately. At high temperatures RR is unimportant in comparison to DR so relativistic effects of the colliding electron need not be considered.

$\mathrm{Gu}$ (2003a) has calculated RR rate coefficients for ions of $\mathrm{Mg}, \mathrm{Si}, \mathrm{S}, \mathrm{Ar}, \mathrm{Ca}, \mathrm{Fe}$, and Ni for bare through F-like ions using FAC. Badnell (2006d) has calculated RR rate coefficients for all elements from $\mathrm{H}$ through to $\mathrm{Zn}$ for the bare through $\mathrm{Na}$ like isoelectronic sequences using AUTOSTRUCTURE. These AUTOSTRUCTURE data are available online (Badnell 2006b).

The AUTOSTRUCTURE results agree with those of Verner $\&$ Ferland (1996) to better than 5\% in the CIE zone. The results of Gu (2003a) and Badnell (2006b) agree to within $\sim 10 \%$ in the $\mathrm{CIE}$ formation zone, except for the $\mathrm{H}$-like ions of $\mathrm{Ar}, \mathrm{Ca}, \mathrm{Fe}$, and $\mathrm{Ni}$. For these ions, the FAC rate coefficients of $\mathrm{Gu}$ (2003a) are systematically smaller than the AUTOSTRUCTURE data of Badnell (2006b). The FAC results show negligible differences with the AUTOSTRUCTURE data at the low-temperature limit of the CIE formation zone, but these differences rise to $\sim 20 \%$ at the high-temperature limit. For these four H-like ions in this temperature range, RR dominates over DR. It should be noted, however, that in CIE the total electron-ion recombination rate is generally dominated by DR rather than RR. So uncertainties in RR data typically have less of an effect than those of DR data for fractional abundance calculations of most ions in CIE.

For ionization stages not included in the calculations of Badnell (2006b) and $\mathrm{Gu}$ (2003a), we use the RR rate coefficients recommended by Mazzotta et al. (1998) for elements up to and including $\mathrm{Ni}$ and those recommended by P. Mazzotta (2000, private communication) for $\mathrm{Cu}$ and $\mathrm{Zn}$. The sources of RR data used in our CIE calculations are listed in Tables 2 and 3.

\section{UNIFIED DR + RR CALCULATIONS}

Nahar \& Pradhan (1997) have presented theoretical unified electron-ion recombination rate coefficients (i.e., DR $+\mathrm{RR}$ ). The currently available data from these works include all ionization stages of C (Nahar \& Pradhan 1997; Nahar et al. 2000), N (Nahar \& Pradhan 1997; Nahar 2006), and O (Nahar 1999; Nahar \& Pradhan 2006); the bare, H-, and He-like ions of F (Nahar 2006), $\mathrm{Ne}$ (Nahar \& Pradhan 2006), Fe (Nahar et al. 2001), and Ni (Nahar 2005b); and B-like Ar (Nahar 2005a). We have compared these results with the summed DR + RR results from the AUTOSTRUCTURE calculations (Badnell 2006a, 2006b).

In the CIE formation zone, agreement is within $20 \%$ for $\mathrm{C}^{q+}$ $\left(q=1,2,4\right.$, and 5), $\mathrm{N}^{q^{+}}\left(q=3,4\right.$, and 6), $\mathrm{O}^{q^{+}}(q=1,2,4$, and 5), $\mathrm{F}^{q^{+}}(q=7$ and 8$), \mathrm{Ne}^{q^{+}}(q=8$ and 9$), \mathrm{Ar}^{13+}$, and $\mathrm{Ni}^{q^{+}}(q=26$ and 27). It is within $30 \%$ for $\mathrm{N}^{q^{+}}(q=2$ and 5$), \mathrm{O}^{q+}(q=3$ and 7$)$, and $\mathrm{Fe}^{25+}$. For the bare ions, where there is no DR contribution to the recombination rate coefficient, agreement is to within a few percent. The only ions that have differences greater than $\sim 30 \%$ are $\mathrm{C}^{3+}, \mathrm{N}^{1+}$, and $\mathrm{Fe}^{24+}$. 

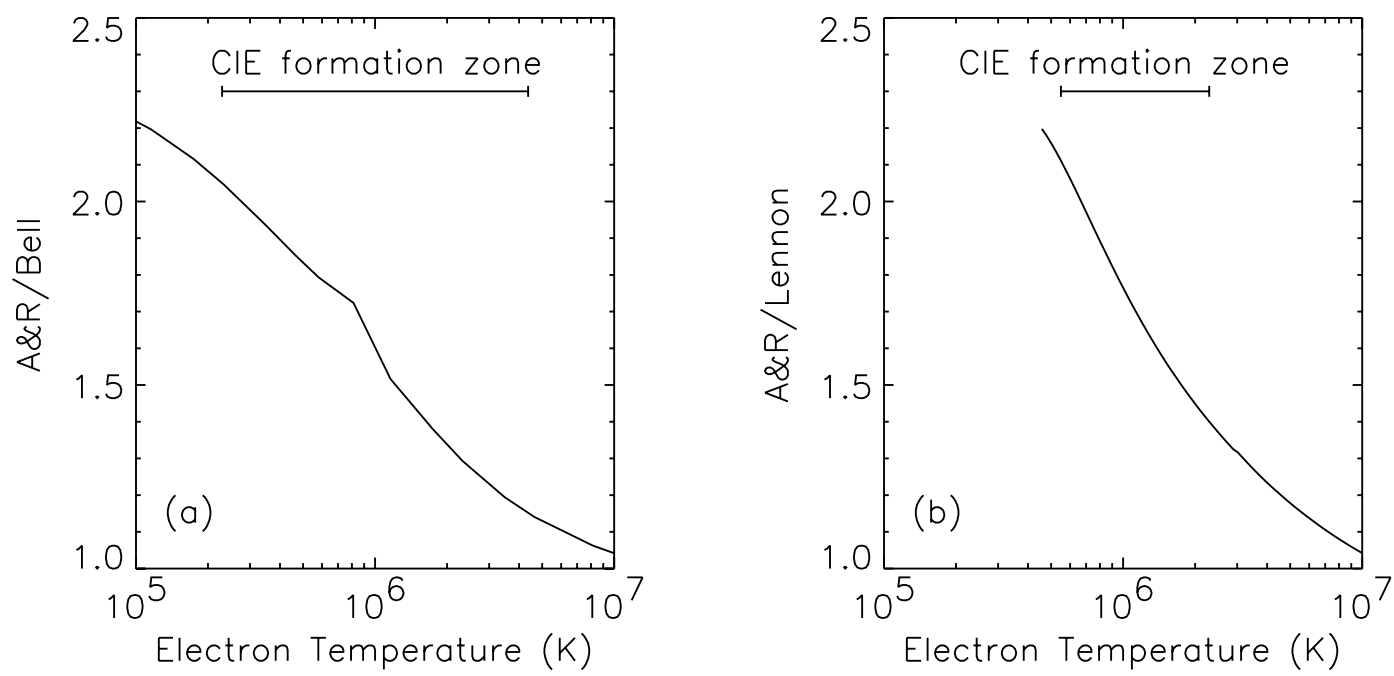

Fig. 1.-Ratio of the recommended EII rate coefficients of Arnaud \& Rothenflug (1985, A\&R) relative to the recommended data of (a) Bell et al. (1983) for He-like $\mathrm{O}^{6+}$ and $(b)$ Lennon et al. (1988) for O-like $\mathrm{S}^{8+}$. The horizontal bars show the temperature range over which these ions form in CIE.

For the $\mathrm{C}^{3+}$ ion the difference is $\sim 35 \%$. However, the results of Nahar \& Pradhan (2003) were calculated using LS-coupling for this ion and are in good agreement (better than 18\%) with the LScoupling results of AUTOSTRUCTURE (unpublished). The CIE peak DR rate coefficient for $\mathrm{C}^{3+}$ is enhanced by $30 \%$ when using intermediate coupling. Using such a coupling scheme, Pradhan et al. (2001) have carried out Breit-Pauli $R$-matrix recombination calculations for $\mathrm{C}^{3+}$ so as to compare with experiment but, to our knowledge, no Maxwellian rate coefficient has been made publicly available. We expect their data would be in better agreement with the summed DR + RR AUTOSTRUCTURE results.

The disagreement in the $\mathrm{N}^{1+}$ rate coefficient is largest at the low-temperature end of the CIE range (up to $60 \%$ at $10^{4} \mathrm{~K}$ ), where the $2 s^{2} 2 p^{4}{ }^{2} D$ DR resonance dominates. The source of this difference may lie in the energy used for this resonance. The AUTOSTRUCTURE results are in close agreement with those of Nussbaumer \& Storey (1983). Both use the observed position of this resonance. The difference is unlikely to be due to fine structure as DR via fine structure core excitations does not become important for this ion until below $10^{3} \mathrm{~K}$, well outside of the CIE range.

For $\mathrm{Fe}^{24+}$ the calculations of Nahar et al. (2001) track the RR calculations of Badnell (2006b) closely; but above $10^{7} \mathrm{~K}$, where the DR contribution to the total recombination rate coefficient becomes important, we find the Nahar et al. (2001) results to be around $45 \%$ larger than the summed (DR $+R R$ ) AUTOSTRUCTURE results. The source of this difference is unclear, but Gorczyca \& Badnell (1997) have shown that DR resonance interference for $\mathrm{Fe}^{24+}$ is negligible so this is unlikely to be the cause. The AUTOSTRUCTURE RR rate coefficients differ by no more than 5\% from those of Verner \& Ferland (1996) over the entire CIE temperature range, while the DR rate coefficients differ by no more than $10 \%$ from those of Gu (2003b) over this range.

\section{ELECTRON IMPACT IONIZATION}

Electron impact ionization (EII) can occur through either direct ionization or indirect processes such as excitation-autoionization (EA) and resonant-excitation double autoionization (REDA). Direct ionization is a nonresonant process. Direct outer-shell ionization typically changes the charge of the initial atom or ion by one. Direct inner-shell ionization produces a hole in the shell and a free electron. As the ion stabilizes to fill the hole, up to six Auger electrons can be emitted (Kaastra \& Mewe 1993; Gorczyca et al. 2003). EA occurs when an incident electron collisionally excites an ion to a state that then decays by autoionization rather than radiative decay. REDA begins when the incident electron is captured by an ion and simultaneously excites a bound electron of the ion. REDA is complete when this recombined system autoionizes by emission of two electrons. Thus, the initial ion has moved one higher in charge state. For ions with certain electron configurations, such as those with one or two valence electrons, EA and, to a lesser extent, REDA can significantly enhance ionization cross sections compared to the direct ionization contribution (e.g., Linkemann et al. 1995).

The most recent set of CIE calculations (Mazzotta et al. 1998) used the recommended data of Arnaud \& Rothenflug (1985) and Arnaud \& Raymond (1992). These EII data are derived from a combination of laboratory measurements and theoretical calculations. Other workers have derived recommended rate coefficients using essentially the same measurements and calculations (Bell et al. 1983; Pindzola et al. 1987; Lennon et al. 1988). All of these recommended EII rate coefficients have been compared by Kato et al. (1991). Taking into account known typographical errors in the recommended EII data, Kato et al. found differences between the various recommended data of up to a factor of 2-3 for many ions (see, e.g., Fig. 1). These differences are not in the fits to the data but in the derived recommended data. This is somewhat surprising considering that the recommended rate coefficients are basically all derived from the same experimental and theoretical data.

In the present paper we use the EII rate coefficients for all ionization states of H through Ni from Mazzotta et al. (1998). This means that any and all subsequent differences between our new fractional abundances and those of Mazzotta et al. (1998) can be attributed to the changes in the recombination rate coefficients used (barring any computational or round-off errors). For $\mathrm{Cu}$ and $\mathrm{Zn}$ we use the recommended rate coefficients of P. Mazzotta (2000, private communication) based on extrapolation of the fitting parameters from other elements. The sources of EII data used in our CIE calculations are listed in Tables 2 and 3.

Mazzitelli \& Mattioli (2002) have also published EII rate coefficients for $\mathrm{Cu}$ and $\mathrm{Zn}$, but they differ from the P. Mazzotta (2000, private communication) data only for the lowest three ionization stages of $\mathrm{Cu}$ and the lowest four ionization stages of $\mathrm{Zn}$. For these seven ions, however, the data of Mazzitelli \& Mattioli do not offer any significant improvement on the Mazzotta data as the Mazzitelli \& Mattioli data are taken from sources that predate the Mazzotta work (Lotz 1968; Higgins et al. 1989). Since the intention of our paper is to investigate the effects of updated 
recombination rate coefficients, and for consistency with the comparisons for other elements, we use the Mazzotta EII rate coefficients for $\mathrm{Cu}$ and $\mathrm{Zn}$.

A fully relativistic treatment of electron impact ionization is often required for highly ionized species, which require much higher incident electron energies to ionize. For example, the ionization of near fully stripped $U$ is highly dependent on the relativistic treatment (Pindzola \& Buie 1998), particularly for $s$-orbitals. On the other hand, Loch et al. (2005) found a semirelativistic treatment of $\mathrm{W}^{9+}$ at $5 \mathrm{keV}$ to be in close agreement with experiment. The same study showed that a fully relativistic treatment was not required until $\mathrm{W}^{64+}$. For all lower tungsten ion stages, a semirelativistic treatment produced good results. Since we do not consider elements above $\mathrm{Zn}$ in this work, theoretical calculations using a fully relativistic treatment are not needed for the present CIE modeling. A semirelativistic approach should be able to produce accurate results for the higher charge states of the ions in this work.

It is not clear, however, that reliable semirelativistic calculations exist among the currently used recommended EII rate coefficients. We have already mentioned the problems noted by Kato et al. (1991). In addition, much of the data are based on experiments with unknown metastable fractions. The resulting rate coefficients represent some average over a distribution of ground state and metastable populations. This is often an acceptable approximation for magnetically confined fusion plasmas, which can have high metastable ion content. But this is generally unsuitable for astrophysical plasmas of the type considered here where the ions are in their ground state. Finally, the recommended EII data currently used by the astrophysics community has not undergone any significant revision or laboratory benchmarking since around 1990. It is clear that an updating of the EII database is sorely needed.

\section{CHARGE TRANSFER}

Charge transfer (CT), also known as charge exchange or electron capture, is the reaction whereby an ion captures an electron from a donor atom. For plasmas of cosmic abundances, this is typically atomic hydrogen but, in some instances, can be neutral helium or other neutral atoms.

The importance of CT with $\mathrm{H}$ can be readily demonstrated (e.g., Kingdon \& Ferland 1996). In CIE, CT is most important for near-neutral systems, up to 4 times ionized (Arnaud \& Rothenflug 1985). Using the data of Badnell (2006a, 2006b) and Gu (2003b, 2003a, 2004) for these ions, a typical rate coefficient for $D R+R R$ is on the order of $\alpha_{\mathrm{DR}+\mathrm{RR}} \approx 10^{-11} \mathrm{~cm}^{3} \mathrm{~s}^{-1}$. A large CT rate coefficient is on the order of $\alpha_{\mathrm{CT}} \approx 10^{-9} \mathrm{~cm}^{3} \mathrm{~s}^{-1}$ (Kingdon \& Ferland 1996). Using these values one finds that, for a given ion, the ratio of the $\mathrm{CT}$ to $\mathrm{DR}+\mathrm{RR}$ rates is given by

$$
\frac{R_{\mathrm{CT}}}{R_{\mathrm{DR}+\mathrm{RR}}}=\frac{\alpha_{\mathrm{CT}} n_{\mathrm{H}^{0}}}{\alpha_{\mathrm{DR}+\mathrm{RR}} n_{e}} \approx 10^{2} \frac{n_{\mathrm{H}^{0}}}{n_{e}} \approx 10^{2} \frac{n_{\mathrm{H}^{0}}}{n_{\mathrm{H}^{+}}},
$$

where $n_{\mathrm{H}^{0}}$ is the neutral $\mathrm{H}$ density, $n_{e}$ is the electron density, and $n_{\mathrm{H}^{+}}$is the $\mathrm{H}^{+}$density. The last approximation makes use of $n_{\mathrm{e}} \approx$ $n_{\mathrm{H}^{+}}$for plasmas with cosmic abundances. As one can see, the CT rate will be equal to or greater than the $\mathrm{DR}+\mathrm{RR}$ rate provided that $n_{\mathrm{H}^{0}} / n_{\mathrm{H}^{+}} \gtrsim 0.01$. This inequality holds for electron temperatures $T_{\mathrm{e}} \lesssim 25,000 \mathrm{~K}$ (see Fig. 2.1 and Table 4).

Arnaud \& Rothenflug (1985) have investigated the effects of CT on CIE and found the process to be important for a number of ions of astrophysical abundance. Those they list for CT with $\mathrm{H}$ are $\mathrm{He}^{q+}(q=1-2) ; \mathrm{C}^{q^{+}}, \mathrm{N}^{q^{+}}, \mathrm{O}^{q^{+}}$, and $\mathrm{S}^{q^{+}}(q=1-4)$; and $\mathrm{Ne}^{q^{+}}$, $\mathrm{Mg}^{q+}, \mathrm{Si}^{q+}$, and $\mathrm{Ar}^{q+}(q=2-4)$. For CT with He, they list $\mathrm{C}^{q^{+}}$, $\mathrm{N}^{q^{+}}, \mathrm{O}^{q+}, \mathrm{Ne}^{q+}$, and $\mathrm{Ar}^{q+}(q=2-4)$; and $\mathrm{Mg}^{q+}, \mathrm{Si}^{q+}$, and $\mathrm{S}^{q^{+}}$ $(q=3-4)$. The reverse reaction, $\mathrm{CT}$ ionization with $\mathrm{H}^{+}$, was also found to be comparable to EII for $\mathrm{O}^{0+}, \mathrm{Si}^{0+}, \mathrm{S}^{0+}, \mathrm{Mg}^{1+}$, and $\mathrm{Si}^{1+}$. $\mathrm{CT}$ ionization with $\mathrm{He}^{1+}$ was found to be important for $\mathrm{C}^{1+}, \mathrm{N}^{1+}$, $\mathrm{Si}^{1+}, \mathrm{Si}^{2+}, \mathrm{S}^{1+}, \mathrm{S}^{2+}$, and $\mathrm{Ar}^{1+}$. Many of the ions listed in this paragraph form at temperatures above $25,000 \mathrm{~K}$. This points out the crudeness of our above back-of-the-envelope estimate. Clearly, a more detailed study is needed using data more modern than that used by Arnaud \& Rothenflug (1985).

We will incorporate CT into our results in a future work. Until then, our CIE results at low temperatures should be used with caution, particularly for temperatures $\lesssim 25,000 \mathrm{~K}$, where neutral $\mathrm{H}$ is abundant.

\section{COLLISIONAL IONIZATION EQUILIBRIUM CALCULATION}

We work in the coronal approximation where each ionization stage is represented by its ground population only, i.e., metastable populations are assumed zero. We neglect the effects of any radiation field, three-body processes, charge transfer, and electron density effects.

The total abundance of element $\mathrm{X}$ is given by

$$
N_{\mathrm{tot}}=\sum_{i=0}^{Z} N^{i}
$$

where $N^{q}$ is the population of ion $\mathrm{X}^{q+}, q$ is the charge, and $Z$ is the atomic number of X. The fractional abundance of charge state $q$ is then given by

$$
f^{q}=\frac{N^{q}}{N_{\text {tot }}} .
$$

This leads naturally to the normalization

$$
\sum_{i=0}^{Z} f^{i}=1
$$

For a given system, the nearby charge stages are linked by the total recombination and ionization coefficients. For the present calculations, the total recombination coefficient is the sum of the DR and RR rate coefficients. The total ionization rate coefficient is simply the EII rate coefficient. For the more general CIE case, one would need also to account for CT recombination and ionization. For recombination from stage $q$ to $q-1$, we write the total recombination rate coefficient as $\alpha_{\text {tot }}^{q \rightarrow q-1}$ and, for ionization from stage $q$ to stage $q+1$, we write the total ionization rate coefficient as $S_{\text {tot }}^{q \rightarrow q+1}$. Here we only consider changes in charge state of $\Delta q= \pm 1$, as has commonly be done in the past for CIE calculations. Changes of $\Delta q> \pm 1$ will be considered in future work.

In coronal equilibrium, the populations are unchanging in time and can be written in matrix form as

$$
N_{\text {tot }} \frac{d}{d t}\left[\begin{array}{c}
f^{0} \\
f^{1} \\
\vdots
\end{array}\right]=\left[\begin{array}{c}
0 \\
0 \\
\vdots
\end{array}\right]
$$

In terms of $\alpha_{\text {tot }}, S_{\text {tot }}$, and electron density, $n_{e}$, the populations can be written as

$$
N_{\mathrm{tot}} n_{e}\left[\begin{array}{ccc}
-S_{\mathrm{tot}}^{0 \rightarrow 1} & \alpha_{\mathrm{tot}}^{1 \rightarrow 0} & 0 \\
S_{\mathrm{tot}}^{0 \rightarrow 1} & -\alpha_{\mathrm{tot}}^{1 \rightarrow 0}-S_{\mathrm{tot}}^{1 \rightarrow 2} & \alpha_{\mathrm{tot}}^{2 \rightarrow 1} \\
0 & S_{\mathrm{tot}}^{1 \rightarrow 2} & \ddots
\end{array}\right]\left[\begin{array}{c}
f^{0} \\
f^{1} \\
\vdots
\end{array}\right]=\left[\begin{array}{c}
0 \\
0 \\
\vdots
\end{array}\right] .
$$


TABLE 4

Sample CiE Fractional Abundances (AUtOstructure-based Results): Iron

\begin{tabular}{|c|c|c|c|c|c|c|c|c|c|c|c|c|c|c|}
\hline $\log (T)$ & $\mathrm{Fe}^{0+}$ & $\mathrm{Fe}^{1+}$ & $\mathrm{Fe}^{2+}$ & $\mathrm{Fe}^{3+}$ & $\mathrm{Fe}^{4+}$ & $\mathrm{Fe}^{5+}$ & $\mathrm{Fe}^{6+}$ & $\mathrm{Fe}^{7+}$ & $\mathrm{Fe}^{8+}$ & $\mathrm{Fe}^{9+}$ & $\mathrm{Fe}^{10+}$ & $\mathrm{Fe}^{11+}$ & $\mathrm{Fe}^{12+}$ & $\mathrm{Fe}^{13+}$ \\
\hline $4.00 \ldots \ldots \ldots \ldots \ldots \ldots$ & 0.916 & 0.056 & 4.006 & 15.000 & 15.000 & 15.000 & 15.000 & 15.000 & 15.000 & 15.000 & 15.000 & 15.000 & 15.000 & 15.000 \\
\hline $4.10 \ldots \ldots \ldots \ldots \ldots \ldots$ & 1.450 & 0.019 & 2.165 & 15.000 & 15.000 & 15.000 & 15.000 & 15.000 & 15.000 & 15.000 & 15.000 & 15.000 & 15.000 & 15.000 \\
\hline $4.20 \ldots$. & 1.981 & 0.085 & 0.776 & 8.101 & 15.000 & 15.000 & 15.000 & 15.000 & 15.000 & 15.000 & 15.000 & 15.000 & 15.000 & 15.000 \\
\hline $4.30 .$. & 2.883 & 0.589 & 0.130 & 5.069 & 15.000 & 15.000 & 15.000 & 15.000 & 15.000 & 15.000 & 15.000 & 15.000 & 15.000 & 15.000 \\
\hline $4.40 \ldots$. & 3.933 & 1.291 & 0.023 & 3.046 & 10.640 & 15.000 & 15.000 & 15.000 & 15.000 & 15.000 & 15.000 & 15.000 & 15.000 & 15.000 \\
\hline $4.50 \ldots$. & 4.698 & 1.747 & 0.021 & 1.520 & 6.727 & 15.000 & 15.000 & 15.000 & 15.000 & 15.000 & 15.000 & 15.000 & 15.000 & 15.000 \\
\hline $4.60 .$. & 5.371 & 2.145 & 0.158 & 0.527 & 3.813 & 10.373 & 15.000 & 15.000 & 15.000 & 15.000 & 15.000 & 15.000 & 15.000 & 15.000 \\
\hline $4.70 \ldots \ldots \ldots$ & 6.163 & 2.688 & 0.507 & 0.170 & 1.969 & 6.405 & 13.158 & 15.000 & 15.000 & 15.000 & 15.000 & 15.000 & 15.000 & 15.000 \\
\hline $4.80 \ldots \ldots$ & 6.947 & 3.245 & 0.897 & 0.127 & 0.898 & 3.638 & 8.368 & 15.000 & 15.000 & 15.000 & 15.000 & 15.000 & 15.000 & 15.000 \\
\hline $4.90 .$. & 7.784 & 3.872 & 1.369 & 0.279 & 0.380 & 1.843 & 5.095 & 10.166 & 15.000 & 15.000 & 15.000 & 15.000 & 15.000 & 15.000 \\
\hline $5.00 .$. & 8.732 & 4.623 & 1.972 & 0.610 & 0.224 & 0.835 & 3.049 & 6.479 & 11.453 & 15.000 & 15.000 & 15.000 & 15.000 & 15.000 \\
\hline $5.10 .$. & 9.801 & 5.504 & 2.709 & 1.101 & 0.322 & 0.370 & 1.808 & 4.080 & 7.575 & 15.000 & 15.000 & 15.000 & 15.000 & 15.000 \\
\hline $5.20 \ldots$ & 10.947 & 6.470 & 3.532 & 1.695 & 0.581 & 0.208 & 1.023 & 2.491 & 4.934 & 12.007 & 15.000 & 15.000 & 15.000 & 15.000 \\
\hline $5.30 \ldots \ldots$ & 12.164 & 7.514 & 4.430 & 2.376 & 0.969 & 0.250 & 0.544 & 1.405 & 3.056 & 8.535 & 14.671 & 15.000 & 15.000 & 15.000 \\
\hline $5.40 \ldots \ldots$ & 13.504 & 8.685 & 5.453 & 3.190 & 1.522 & 0.503 & 0.350 & 0.720 & 1.741 & 5.916 & 10.608 & 15.000 & 15.000 & 15.000 \\
\hline $5.50 \ldots \ldots$ & 15.000 & 10.023 & 6.640 & 4.174 & 2.268 & 0.984 & 0.441 & 0.395 & 0.901 & 4.005 & 7.517 & 11.373 & 15.000 & 15.000 \\
\hline $5.60 \ldots \ldots$ & 15.000 & 11.506 & 7.968 & 5.304 & 3.179 & 1.655 & 0.766 & 0.361 & 0.434 & 2.658 & 5.206 & 8.100 & 11.438 & 15.000 \\
\hline $5.70 \ldots \ldots$ & 15.000 & 13.060 & 9.365 & 6.506 & 4.176 & 2.431 & 1.232 & 0.510 & 0.215 & 1.715 & 3.476 & 5.569 & 8.043 & 11.515 \\
\hline $5.80 \ldots \ldots$ & 15.000 & 14.627 & 10.774 & 7.723 & 5.199 & 3.248 & 1.767 & 0.762 & 0.147 & 1.049 & 2.166 & 3.587 & 5.346 & 7.950 \\
\hline $5.90 \ldots \ldots \ldots \ldots \ldots \ldots$ & 15.000 & 15.000 & 12.211 & 8.970 & 6.260 & 4.116 & 2.377 & 1.113 & 0.216 & 0.620 & 1.208 & 2.061 & 3.221 & 5.102 \\
\hline $6.00 \ldots \ldots \ldots \ldots \ldots \ldots$ & 15.000 & 15.000 & 13.783 & 10.357 & 7.468 & 5.140 & 3.164 & 1.662 & 0.512 & 0.495 & 0.640 & 1.010 & 1.664 & 2.936 \\
\hline $6.10 \ldots \ldots$ & 15.000 & 15.000 & 15.000 & 12.049 & 8.988 & 6.482 & 4.288 & 2.565 & 1.183 & 0.805 & 0.574 & 0.531 & 0.751 & 1.502 \\
\hline $6.20 \ldots \ldots$ & 15.000 & 15.000 & 15.000 & 14.088 & 10.860 & 8.184 & 5.788 & 3.856 & 2.260 & 1.566 & 1.007 & 0.609 & 0.451 & 0.752 \\
\hline $6.30 \ldots$. & 15.000 & 15.000 & 15.000 & 15.000 & 13.129 & 10.287 & 7.704 & 5.575 & 3.779 & 2.805 & 1.955 & 1.247 & 0.755 & 0.663 \\
\hline $6.40 \ldots \ldots$ & 15.000 & 15.000 & 15.000 & 15.000 & 15.000 & 12.798 & 10.040 & 7.723 & 5.738 & 4.509 & 3.398 & 2.418 & 1.627 & 1.187 \\
\hline $6.50 .$. & 15.000 & 15.000 & 15.000 & 15.000 & 15.000 & 15.000 & 12.409 & 9.912 & 7.748 & 6.287 & 4.937 & 3.713 & 2.653 & 1.904 \\
\hline $6.60 \ldots$ & 15.000 & 15.000 & 15.000 & 15.000 & 15.000 & 15.000 & 14.647 & 11.978 & 9.642 & 7.966 & 6.397 & 4.952 & 3.648 & 2.622 \\
\hline $6.70 \ldots$ & 15.000 & 15.000 & 15.000 & 15.000 & 15.000 & 15.000 & 15.000 & 13.932 & 11.432 & 9.557 & 7.784 & 6.137 & 4. & 3.335 \\
\hline $6.80 \ldots$ & 15.000 & 15.000 & 15.000 & 15.000 & 15.000 & 15.000 & 15.000 & 15.000 & 13.182 & 11.119 & 9.156 & 7.322 & 5.590 & 4.089 \\
\hline $6.90 \ldots$ & 15.000 & 15.000 & 15.000 & 15.000 & 15.000 & 15.000 & 15.000 & 15.000 & 14.983 & 12.744 & 10.602 & 8.592 & 6.670 & 4.964 \\
\hline $7.00 \ldots$ & 15.000 & 15.000 & 15.000 & 15.000 & 15.000 & 15.000 & 15.000 & 15.000 & 15.000 & 14.547 & 12.236 & 10.061 & 7.963 & 6.068 \\
\hline $7.10 \ldots$ & 15.000 & 15.000 & 15.000 & 15.000 & 15.000 & 15.000 & 15.000 & 15.000 & 15.000 & & 14.187 & 11.857 & 9.593 & 7.524 \\
\hline $7.20 \ldots$. & 15.000 & 15.000 & 15.000 & 15.000 & 15.000 & 15.000 & 15.000 & 15.000 & 15.000 & 15.000 & 15.000 & 13.991 & 11.571 & 9.339 \\
\hline $7.30 \ldots$ & 15.000 & 15.000 & 15.000 & 15.000 & 15.000 & 15.000 & 15.000 & 15.000 & 15.000 & 15.000 & 15.000 & 15.000 & 13.677 & 11.288 \\
\hline $7.40 \ldots$ & 15.000 & 15.000 & 15.000 & 15.000 & 15.000 & 15.000 & 15.000 & 15.000 & 15.000 & 15.000 & 15.000 & 15.000 & 15.000 & 13.198 \\
\hline $7.50 \ldots \ldots$ & 15.000 & 15.000 & 15.000 & 15.000 & 15.000 & 15.000 & 15.000 & 15.000 & 15.000 & & 15.000 & 15.000 & 15.000 & 15.000 \\
\hline $7.60 \ldots \ldots$ & 15.000 & 15.000 & 15.000 & 15.000 & 15.000 & 15.000 & 15.000 & 15.000 & 15.000 & 15.000 & 15.000 & 15.000 & 15.000 & 15.000 \\
\hline 7.70 .................... & 15.000 & 15.000 & 15.000 & 15.000 & 15.000 & 15.000 & 15.000 & 15.000 & 15.000 & 15.000 & 15.000 & 15.000 & 15.000 & 15.000 \\
\hline $7.80 \ldots \ldots \ldots \ldots \ldots \ldots$ & 15.000 & 15.000 & 15.000 & 15.000 & 15.000 & 15.000 & 15.000 & 15.000 & 15.000 & 15.000 & 15.000 & 15.000 & 15.000 & 15.000 \\
\hline $7.90 \ldots \ldots \ldots \ldots \ldots \ldots$ & 15.000 & 15.000 & 15.000 & 15.000 & 15.000 & 15.000 & 15.000 & 15.000 & 15.000 & 15.000 & 15.000 & 15.000 & 15.000 & 15.000 \\
\hline $8.00 \ldots \ldots \ldots \ldots \ldots \ldots$ & 15.000 & 15.000 & 15.000 & 15.000 & 15.000 & 15.000 & 15.000 & 15.000 & 15.000 & 15.000 & 15.000 & 15.000 & 15.000 & 15.000 \\
\hline $8.10 \ldots \ldots \ldots \ldots \ldots \ldots$ & 15.000 & 15.000 & 15.000 & 15.000 & 15.000 & 15.000 & 15.000 & 15.000 & 15.000 & 15.000 & 15.000 & 15.000 & 15.000 & 15.000 \\
\hline $8.20 \ldots \ldots \ldots \ldots \ldots \ldots$ & 15.000 & 15.000 & 15.000 & 15.000 & 15.000 & 15.000 & 15.000 & 15.000 & 15.000 & 15.000 & 15.000 & 15.000 & 15.000 & 15.000 \\
\hline $8.30 \ldots \ldots \ldots \ldots \ldots \ldots \ldots$ & 15.000 & 15.000 & 15.000 & 15.000 & & 15.000 & 15.000 & 15.000 & 15.000 & 15.000 & 15.000 & 15.000 & 15.000 & 15.000 \\
\hline $8.40 \ldots \ldots \ldots \ldots \ldots \ldots$ & 15.000 & 15.000 & 15.000 & 15.000 & 15.000 & 15.000 & 15.000 & 15.000 & 15.000 & 15.000 & 15.000 & 15.000 & 15.000 & 15.000 \\
\hline $8.50 \ldots \ldots \ldots \ldots \ldots \ldots$ & 15.000 & 15.000 & 15.000 & 15.000 & 15.000 & 15.000 & 15.000 & 15.000 & 15.000 & 15.000 & 15.000 & 15.000 & 15.000 & 15.000 \\
\hline $8.60 \ldots \ldots$ & 15.000 & 15.000 & 15.000 & 15.000 & 15.000 & 15.000 & 15.000 & 15.000 & 15.000 & 15.000 & 15.000 & 15.000 & 15.000 & 15.000 \\
\hline $8.70 \ldots \ldots$ & 15.000 & 15.000 & 15.000 & 15.000 & 15.000 & 15.000 & 15.000 & 15.000 & 15.000 & 15.000 & 15.000 & 15.000 & 15.000 & 15.000 \\
\hline $8.80 \ldots \ldots$ & 15.000 & 15.000 & 15.000 & 15.000 & 15.000 & 15.000 & 15.000 & 15.000 & 15.000 & 15.000 & 15.000 & 15.000 & 15.000 & 15.000 \\
\hline $8.90 \ldots \ldots$. & 15.000 & 15.000 & 15.000 & 15.000 & 15.000 & 15.000 & 15.000 & 15.000 & 15.000 & 15.000 & 15.000 & 15.000 & 15.000 & 15.000 \\
\hline $9.00 \ldots \ldots \ldots \ldots \ldots \ldots$ & 15.000 & 15.000 & 15.000 & 15.000 & 15.000 & 15.000 & 15.000 & 15.000 & 15.000 & 15.000 & 15.000 & 15.000 & 15.000 & 15.000 \\
\hline $\log (T)$ & $\mathrm{Fe}^{14+}$ & $\mathrm{Fe}^{15+}$ & $\mathrm{Fe}^{16+}$ & $\mathrm{Fe}^{17+}$ & $\mathrm{Fe}^{18+}$ & $\mathrm{Fe}^{19+}$ & $\mathrm{Fe}^{20+}$ & $\mathrm{Fe}^{21+}$ & $\mathrm{Fe}^{22+}$ & $\mathrm{Fe}^{23+}$ & $\mathrm{Fe}^{24+}$ & $\mathrm{Fe}^{25+}$ & $\mathrm{Fe}^{26+}$ & \\
\hline $4.00 \ldots \ldots$ & 15.000 & 15.000 & & & & & & & & & & & & \\
\hline $4.10 \ldots \ldots \ldots \ldots . .$. & 15.000 & 15.000 & 15.000 & 15.000 & 15.000 & 15.000 & 15.000 & 15.000 & 15.000 & 15.000 & 15.000 & 15.000 & 15.000 & \\
\hline $4.20 \ldots \ldots \ldots$ & 15.000 & 15.000 & 15.000 & 15.000 & 15.000 & 15.000 & 15.000 & 15.000 & 15.000 & 15.000 & 15.000 & 15.000 & 15.000 & \\
\hline $4.30 \ldots \ldots \ldots \ldots \ldots \ldots$ & 15.000 & 15.000 & 15.000 & 15.000 & 15.000 & 15.000 & 15.000 & 15.000 & 15.000 & 15.000 & 15.000 & 15.000 & 15.000 & \\
\hline $4.40 \ldots \ldots \ldots \ldots \ldots \ldots$ & 15.000 & 15.000 & 15.000 & 15.000 & 15.000 & 15.000 & 15.000 & 15.000 & 15.000 & 15.000 & 15.000 & 15.000 & 15.000 & \\
\hline $4.50 \ldots \ldots \ldots \ldots \ldots \ldots$ & 15.000 & 15.000 & 15.000 & 15.000 & 15.000 & 15.000 & 15.000 & 15.000 & 15.000 & 15.000 & 15.000 & 15.000 & 15.000 & \\
\hline $4.60 \ldots \ldots \ldots \ldots \ldots \ldots$ & 15.000 & 15.000 & 15.000 & 15.000 & 15.000 & 15.000 & 15.000 & 15.000 & 15.000 & 15.000 & 15.000 & 15.000 & 15.000 & \\
\hline $4.70 \ldots \ldots \ldots \ldots \ldots \ldots$ & 15.000 & 15.000 & 15.000 & 15.000 & 15.000 & 15.000 & 15.000 & 15.000 & 15.000 & 15.000 & 15.000 & 15.000 & 15.000 & \\
\hline $4.80 \ldots \ldots \ldots \ldots \ldots \ldots$ & 15.000 & 15.000 & 15.000 & 15.000 & 15.000 & 15.000 & 15.000 & 15.000 & 15.000 & 15.000 & 15.000 & 15.000 & 15.000 & \\
\hline $4.90 \ldots \ldots \ldots \ldots \ldots \ldots$ & 15.000 & 15.000 & 15.000 & 15.000 & 15.000 & 15.000 & 15.000 & 15.000 & 15.000 & 15.000 & 15.000 & 15.000 & 15.000 & \\
\hline $5.00 \ldots \ldots \ldots \ldots \ldots \ldots$ & 15.000 & 15.000 & 15.000 & 15.000 & 15.000 & 15.000 & 15.000 & 15.000 & 15.000 & 15.000 & 15.000 & 15.000 & 15.000 & \\
\hline $5.10 \ldots \ldots \ldots \ldots \ldots \ldots \ldots$ & 15.000 & 15.000 & 15.000 & 15.000 & 15.000 & 15.000 & 15.000 & 15.000 & 15.000 & 15.000 & 15.000 & 15.000 & 15.000 & \\
\hline
\end{tabular}


TABLE 4-Continued

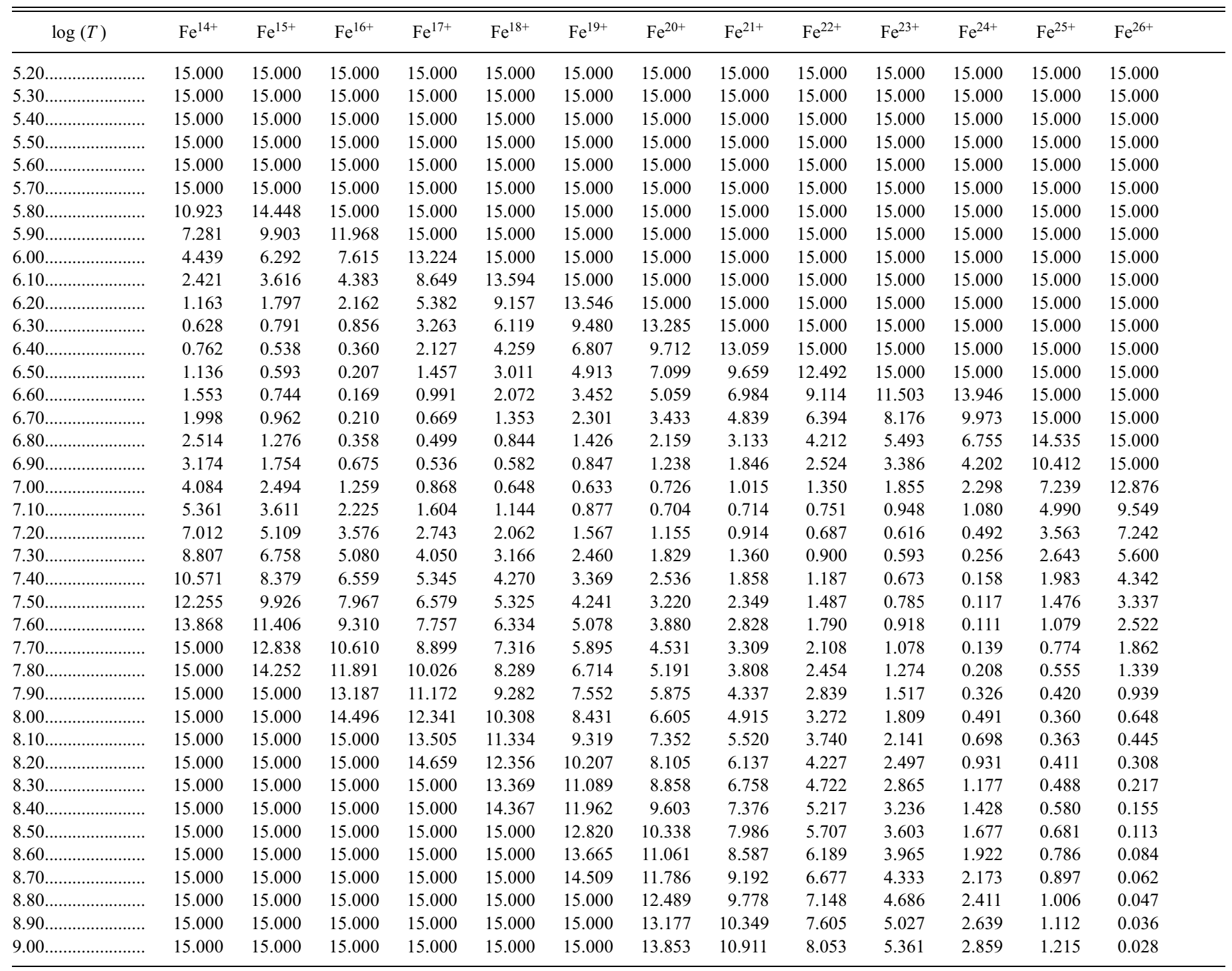

Note.-Table 4 is available in its entirety in the electronic edition of the Astrophysical Journal Supplement. A portion is shown here for guidance regarding its form and content.

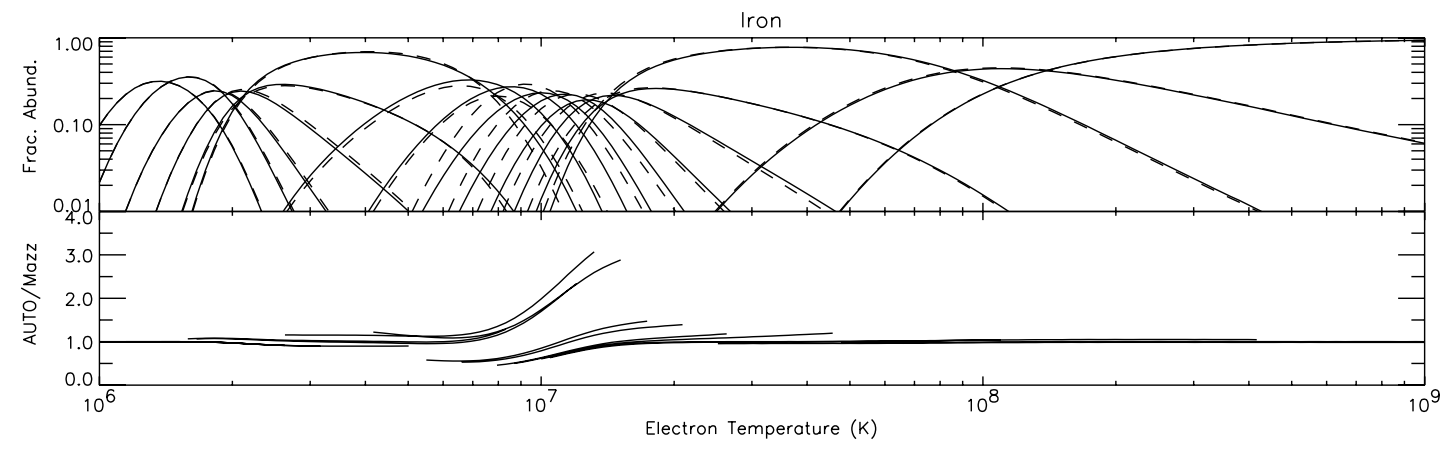

FIG. 2.26.- Ionization fractional abundance vs. electron temperature for Fe.

Fig. SET 2.- AUTOSTRUCTURE-based results. The solid curves of the upper graph show the ionization fractional abundance as calculated using the AUTOSTRUCTURE DR rate coefficients of Badnell (2006a) for H- through Na-like ions and the AUTOSTRUCTURE RR rate coefficients of Badnell (2006b) for bare through Na-like ions. We use the DR and RR rate coefficients of Mazzotta et al. (1998) for ions not calculated by Badnell (2006a, 2006b). The EII rate coefficients used are those of Mazzotta et al. (1998). The dashed curves show the abundances calculated by Mazzotta et al. (1998). The lower graph shows the ratio of the calculated abundances. The lowest ionization stage shown is P-like. Comparison is made only for fractional abundances greater than $10^{-2}$. We label the results using the data of Badnell (2006a, 2006b) as "AUTO" and Mazzotta et al. (1998) as "Mazz." [See the electronic version of the Supplement for Figs. 2.1-2.30.] 


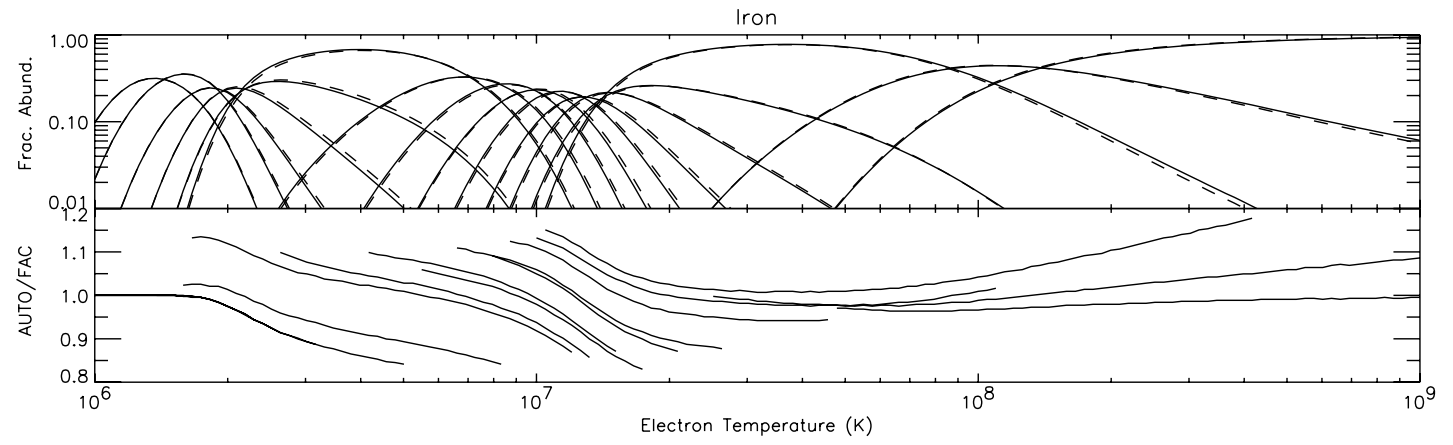

FIG. 3.6.- Ionization fractional abundance vs. electron temperature for Fe.

FIG. SET 3.-FAC-based results. The solid curves of the upper graph show the ionization fractional abundance as calculated using the AUTOSTRUCTURE DR rate coefficients of Badnell (2006a) for H- through Na-like ions and the AUTOSTRUCTURE RR rate coefficients of Badnell (2006b) for bare through Na-like ions. The dashed curves show the abundances as calculated using the FAC DR rate coefficients of Gu (2003b, 2004) for H- through Na-like ions and the FAC RR rate coefficients of $\mathrm{Gu}$ (2003a) for bare through F-like ions. We use the DR and RR rate coefficients of Mazzotta et al. (1998) for ions not calculated by Gu (2003a, 2003b, 2004) or by Badnell (2006a, 2006b). The EII rate coefficients used are those of Mazzotta et al. (1998). The lower graph shows the ratio of the calculated abundances. The lowest ionization stage shown is P-like. Comparison is made only for fractional abundances greater than $10^{-2}$. We label the results using the data of Badnell (2006a, 2006b) as "AUTO" and Gu (2003a, 2003b, 2004) as "FAC." [See the electronic version of the Supplement for Figs. 3.1-3.7.]

We thus have a tridiagonal system in which the solution to all the ionization stage populations is given in terms of any one population. The system is tridiagonal since we consider only changes in charge state of $\Delta q= \pm 1$. Coupling equations (4) and (6) gives $Z+2$ equations with $Z+1$ unknowns. The set of equations are then degenerate, so we divide equation (6) by $N_{\text {tot }} n_{e}$ and then arbitrarily replace the first row of equation (6) with equation (4). This set of equations is then solved using the ionization and recombination rate coefficients detailed previously. Our results are presented in terms of the calculated fractional abundances $f$.

\section{RESULTS}

Figure Set 2 (Figs. 2.1-2.28) show our calculated fractional abundances compared to those of Mazzotta et al. (1998). Mazzotta et al. did not publish results for the ionization balance of $\mathrm{Cu}$ and $\mathrm{Zn}$, so we present our results without comparison (Figs. 2.29 and 2.30). Our calculated fractional abundances are given in tabular form in Table 4 with iron printed as an example. For the elements where DR and RR rate coefficients are also provided by $\mathrm{Gu}$ (2003b, 2003a, 2004), we compare the results using his data with those using the data of Badnell (2006a, 2006b). These comparisons are shown in Figure Set 3. The calculated fractional abundances based on the data of $\mathrm{Gu}$ are given in Table 5. To make these tables easily machine readable, we tabulate fractional abundances down to $10^{-15}$ and fix fractional abundances below this value to $10^{-15}$.

We limit our studies to the temperature range $10^{4}-10^{9} \mathrm{~K}$. The recombination data of Badnell (2006a, 2006b) and Gu (2003b, 2003a, 2004) covers ionization stages from bare through Na-like. For ions with more electrons we use the data recommended by Mazzotta et al. (1998) and P. Mazzotta (2000, private communication). As the CIE calculations move to ionization stages with more electrons than Na-like, which has 11 electrons, the effects of the new DR and RR data decrease, as is expected. These differences become insignificant typically by the time one reaches the Si- or P-like isoelectronic sequence, with 14 and 15 electrons, respectively. Because of this, and to avoid figures becoming overly congested, we generally plot our results only for ionization stages with 15 or fewer electrons. The lower temperature limit shown is also increased to focus on these ionization stages. Where all ionization stages are not shown, the figure caption indicates such.

\section{DISCUSSION}

In the discussion below we point out differences in the CIE ionic fractional abundances we have calculated using the AUTOSTRUCTURE data of Badnell (2006a, 2006b) with calculations using other data. First, we compare to the recommended CIE results of Mazzotta et al. (1998), and then to the CIE results using the FAC data of Gu (2003b, 2003a, 2004). We highlight ions and temperatures where the differences are larger than $20 \%$. The differences quoted are the percentage increase or decrease in our calculations relative to the fractional abundances of Mazzotta et al. (1998) or relative to those calculated using the data of $\mathrm{Gu}$ (2003b, 2003a, 2004). All differences discussed below can be attributed to the use of different DR and RR data sets.

To simplify the comparison, we point out where there are large differences at peak fractional abundance and at fractional abundances of 0.1 and 0.01 . Table 6 lists ions where our peak abundances differ from those of Mazzotta et al. (1998) by more than $20 \%$, or where the difference in peak formation temperature is $\geq 0.05$ in the dex. This table gives the percentage change in peak fractional abundance and the change in temperature relative to the results of Mazzotta et al. (1998).

It is interesting to note that the differences in our calculated CIE fractional abundances relative to those of Mazzotta et al. (1998) are, in general, much larger than the differences between our results and the results using the data of $\mathrm{Gu}$ (2003b, 2003a, 2004). In the former case, peak abundance differences of nearly $60 \%$ are found (see Fig. 2.21) and the differences can be larger than a factor of 11 (i.e., $1000 \%$ ) at fractional abundances down to 0.01 (see Fig. 2.17). For the latter case, peak abundance differences are within $10 \%$ and differences for fractional abundances down to 0.01 are within $50 \%$. This reflects the fact that the modern DR and RR data are in better agreement with one another than with the older data.

We have not investigated the reliability of the DR and RR data at temperatures where the fractional abundance is $<0.01$; so our calculated fractional abundances must be used with caution outside this range. Comparison of the fractional abundances using the data of Badnell (2006a, 2006b) and Gu (2003b, 2003a, 2004) can be used to give an estimate of how the uncertainties in these modern DR and RR calculations translate into uncertainties in the CIE calculations for fractional abundances below 0.01 . 
TABLE 5

Sample CiE Fractional Abundances (FAC-based Results): Iron

\begin{tabular}{|c|c|c|c|c|c|c|c|c|c|c|c|c|c|c|}
\hline $\log (T)$ & $\mathrm{Fe}^{0+}$ & $\mathrm{Fe}^{1+}$ & $\mathrm{Fe}^{2+}$ & $\mathrm{Fe}^{3+}$ & $\mathrm{Fe}^{4+}$ & $\mathrm{Fe}^{5+}$ & $\mathrm{Fe}^{6+}$ & $\mathrm{Fe}^{7+}$ & $\mathrm{Fe}^{8+}$ & $\mathrm{Fe}^{9+}$ & $\mathrm{Fe}^{10+}$ & $\mathrm{Fe}^{11+}$ & $\mathrm{Fe}^{12+}$ & $\mathrm{Fe}^{13+}$ \\
\hline $4.00 \ldots \ldots \ldots \ldots \ldots \ldots$ & 0.916 & 0.056 & 4.006 & 15.000 & 15.000 & 15.000 & 15.000 & 15.000 & 15.000 & 15.000 & 15.000 & 15.000 & 15.000 & 15.000 \\
\hline $4.10 \ldots \ldots \ldots \ldots \ldots \ldots \ldots$ & 1.450 & 0.019 & 2.165 & 15.000 & 15.000 & 15.000 & 15.000 & 15.000 & 15.000 & 15.000 & 15.000 & 15.000 & 15.000 & 15.000 \\
\hline $4.20 \ldots$ & 1.981 & 0.085 & 0.776 & 8.101 & 15.000 & 15.000 & 15.000 & 15.000 & 15.000 & 15.000 & 15.000 & 15.000 & 15.000 & 15.000 \\
\hline $4.30 \ldots$. & 2.883 & 0.589 & 0.130 & 5.069 & 15.000 & 15.000 & 15.000 & 15.000 & 15.000 & 15.000 & 15.000 & 15.000 & 15.000 & 15.000 \\
\hline $4.40 \ldots \ldots$ & 3.933 & 1.291 & 0.023 & 3.046 & 10.640 & 15.000 & 15.000 & 15.000 & 15.000 & 15.000 & 15.000 & 15.000 & 15.000 & 15.000 \\
\hline $4.50 \ldots \ldots$ & 4.698 & 1.747 & 0.021 & 1.520 & 6.727 & 15.000 & 15.000 & 15.000 & 15.000 & 15.000 & 15.000 & 15.000 & 15.000 & 15.000 \\
\hline $4.60 \ldots \ldots$ & 5.371 & 2.145 & 0.158 & 0.527 & 3.813 & 10.373 & 15.000 & 15.000 & 15.000 & 15.000 & 15.000 & 15.000 & 15.000 & 15.000 \\
\hline $4.70 \ldots \ldots$ & 6.163 & 2.688 & 0.507 & 0.170 & 1.969 & 6.405 & 13.158 & 15.000 & 15.000 & 15.000 & 15.000 & 15.000 & 15.000 & 15.000 \\
\hline $4.80 \ldots \ldots$ & 6.947 & 3.245 & 0.897 & 0.127 & 0.898 & 3.638 & 8.368 & 15.000 & 15.000 & 15.000 & 15.000 & 15.000 & 15.000 & 15.000 \\
\hline $4.90 \ldots$ & 7.784 & 3.872 & 1.369 & 0.279 & 0.380 & 1.843 & 5.095 & 10.166 & 15.000 & 15.000 & 15.000 & 15.000 & 15.000 & 15.000 \\
\hline $5.00 \ldots$ & 8.732 & 4.623 & 1.972 & 0.610 & 0.224 & 0.835 & 3.049 & 6.479 & 11.453 & 15.000 & 15.000 & 15.000 & 15.000 & 15.000 \\
\hline $5.10 \ldots \ldots$ & 9.801 & 5.504 & 2.709 & 1.101 & 0.322 & 0.370 & 1.808 & 4.080 & 7.575 & 15.000 & 15.000 & 15.000 & 15.000 & 15.000 \\
\hline $5.20 \ldots \ldots$ & 10.947 & 6.470 & 3.532 & 1.695 & 0.581 & 0.208 & 1.023 & 2.491 & 4.934 & 12.007 & 15.000 & 15.000 & 15.000 & 15.000 \\
\hline $5.30 \ldots \ldots$ & 12.164 & 7.514 & 4.430 & 2.376 & 0.969 & 0.250 & 0.544 & 1.405 & 3.056 & 8.535 & 14.671 & 15.000 & 15.000 & 15.000 \\
\hline $5.40 \ldots \ldots \ldots \ldots \ldots \ldots$ & 13.504 & 8.685 & 5.453 & 3.190 & 1.522 & 0.503 & 0.350 & 0.720 & 1.741 & 5.916 & 10.608 & 15.000 & 15.000 & 15.000 \\
\hline $5.50 \ldots \ldots \ldots \ldots \ldots \ldots$ & 15.000 & 10.023 & 6.640 & 4.174 & 2.268 & 0.984 & 0.441 & 0.395 & 0.901 & 4.005 & 7.517 & 11.373 & 15.000 & 15.000 \\
\hline $5.60 \ldots \ldots$ & 15.000 & 11.506 & 7.968 & 5.304 & 3.179 & 1.655 & 0.766 & 0.361 & 0.434 & 2.658 & 5.206 & 8.100 & 11.438 & 15.000 \\
\hline $5.70 \ldots \ldots$ & 15.000 & 13.060 & 9.365 & 6.506 & 4.176 & 2.431 & 1.232 & 0.510 & 0.215 & 1.715 & 3.476 & 5.569 & 8.043 & 11.515 \\
\hline $5.80 \ldots \ldots$ & 15.000 & 14.627 & 10.774 & 7.723 & 5.199 & 3.248 & 1.767 & 0.762 & 0.147 & 1.049 & 2.166 & 3.587 & 5.346 & 7.950 \\
\hline $5.90 \ldots \ldots$ & 15.000 & 15.000 & 12.211 & 8.970 & 6.260 & 4.116 & 2.377 & 1.113 & 0.216 & 0.620 & 1.208 & 2.061 & 3.221 & 5.102 \\
\hline $6.00 \ldots$ & 15.000 & 15.000 & 13.783 & 10.357 & 7.468 & 5.140 & 3.164 & 1.662 & 0.512 & 0.495 & 0.640 & 1.010 & 1.664 & 2.936 \\
\hline $6.10 \ldots \ldots$ & 15.000 & 15.000 & 15.000 & 12.049 & 8.988 & 6.482 & 4.288 & 2.565 & 1.183 & 0.805 & 0.574 & 0.531 & 0.751 & 1.502 \\
\hline $6.20 \ldots \ldots$ & 15.000 & 15.000 & 15.000 & 14.088 & 10.860 & 8.183 & 5.787 & 3.856 & 2.260 & 1.566 & 1.007 & 0.608 & 0.450 & 0.752 \\
\hline $6.30 \ldots \ldots \ldots$ & 15.000 & 15.000 & 15.000 & 15.000 & 13.119 & 10.277 & 7.694 & 5.565 & 3.769 & 2.794 & 1.945 & & 0.744 & 0.652 \\
\hline $6.40 \ldots \ldots \ldots \ldots \ldots \ldots$ & 15.000 & 15.000 & 15.000 & 15.000 & 15.000 & 12.763 & 10.006 & 7.689 & 5.704 & 4.475 & 3.364 & & 1.593 & 1.153 \\
\hline $6.50 \ldots \ldots \ldots \ldots \ldots \ldots$ & 15.000 & 15.000 & 15.000 & 15.000 & 15.000 & 15.000 & 12.357 & 9.860 & 7.696 & 6.235 & 4.885 & 3.661 & 2.601 & 1.852 \\
\hline $6.60 \ldots \ldots$ & 15.000 & 15.000 & 15.000 & 15.000 & 15.000 & 15.000 & 14.582 & 11.913 & 9.577 & 7.901 & 6.332 & 4.887 & 3.584 & 2.557 \\
\hline 6.70 ................... & 15.000 & 15.000 & 15.000 & 15.000 & 15.000 & 15.000 & 15.000 & 13.857 & 11.357 & 9.482 & 7.709 & 6.062 & 4.535 & 3.260 \\
\hline $6.80 \ldots \ldots \ldots \ldots \ldots . . . . . . .$. & 15.000 & 15.000 & 15.000 & 15.000 & 15.000 & 15.000 & 15.000 & 15.000 & 13.096 & 11.033 & 9.070 & 7.235 & 5.503 & 4.003 \\
\hline $6.90 \ldots \ldots \ldots$ & 15.000 & 15.000 & 15.000 & 15.000 & 15.000 & 15.000 & 15.000 & 15.000 & 14.883 & 12.644 & 10.502 & 8.492 & 6.570 & 4.864 \\
\hline $7.00 \ldots \ldots$ & 15.000 & 15.000 & 15.000 & 15.000 & 15.000 & 15.000 & 15.000 & 15.000 & 15.000 & 14.427 & 12.116 & 9.942 & 7.843 & 5.948 \\
\hline $7.10 \ldots \ldots$ & 15.000 & 15.000 & 15.000 & 15.000 & 15.000 & 15.000 & 15.000 & 15.000 & 15.000 & 15.000 & 14.035 & 11.706 & 9.442 & 7.372 \\
\hline $7.20 \ldots \ldots$ & 15.000 & 15.000 & 15.000 & 15.000 & 15.000 & 15.000 & 15.000 & 15.000 & 15.000 & 15.000 & 15.000 & 13.806 & 11.386 & 9.153 \\
\hline $7.30 \ldots \ldots \ldots$ & 15.000 & 15.000 & 15.000 & 15.000 & 15.000 & 15.000 & 15.000 & & 15.000 & 15.000 & 15.000 & 15.000 & 13.468 & 11.079 \\
\hline $7.40 \ldots \ldots \ldots \ldots \ldots \ldots$ & 15.000 & 15.000 & 15.000 & 15.000 & 15.000 & 15.000 & 15.000 & 15.000 & 15.000 & 15.000 & 15.000 & 15.000 & 15.000 & 12.975 \\
\hline $7.50 \ldots \ldots \ldots \ldots \ldots$ & 15.000 & 15.000 & 15.000 & 15.000 & 15.000 & 15.000 & 15.000 & 15.000 & 15.000 & 15.000 & 15.000 & 15.000 & 15.000 & 14.785 \\
\hline $7.60 \ldots \ldots$ & 15.000 & 15.000 & 15.000 & 15.000 & 15.000 & 15.000 & 15.000 & 15.000 & 15.000 & 15.000 & 15.000 & 15.000 & 15.000 & 15.000 \\
\hline $7.70 \ldots \ldots \ldots \ldots \ldots \ldots$ & 15.000 & 15.000 & 15.000 & 15.000 & 15.000 & 15.000 & 15.000 & 15.000 & 15.000 & 15.000 & 15.000 & 15.000 & 15.000 & 15.000 \\
\hline $7.80 \ldots \ldots \ldots \ldots \ldots \ldots$ & 15.000 & 15.000 & 15.000 & 15.000 & 15.000 & 15.000 & 15.000 & 15.000 & 15.000 & 15.000 & 15.000 & 15.000 & 15.000 & 15.000 \\
\hline $7.90 \ldots \ldots$ & 15.000 & 15.000 & 15.000 & 15.000 & 15.000 & 15.000 & 15.000 & 15.000 & 15.000 & 15.000 & 15.000 & 15.000 & 15.000 & 15.000 \\
\hline $8.00 \ldots \ldots$ & 15.000 & 15.000 & 15.000 & 15.000 & 15.000 & 15.000 & 15.000 & 15.000 & 15.000 & 15.000 & 15.000 & 15.000 & 15.000 & 15.000 \\
\hline $8.10 \ldots \ldots \ldots \ldots \ldots \ldots$ & 15.000 & 15.000 & 15.000 & 15.000 & 15.000 & 15.000 & 15.000 & 15.000 & 15.000 & 15.000 & 15.000 & 15.000 & 15.000 & 15.000 \\
\hline $8.20 \ldots \ldots \ldots \ldots \ldots \ldots$ & 15.000 & 15.000 & 15.000 & 15.000 & 15.000 & 15.000 & 15.000 & 15.000 & 15.000 & 15.000 & 15.000 & 15.000 & 15.000 & 15.000 \\
\hline $8.30 \ldots \ldots \ldots \ldots \ldots \ldots$ & 15.000 & 15.000 & 15.000 & 15.000 & 15.000 & 15.000 & 15.000 & 15.000 & 15.000 & 15.000 & 15.000 & 15.000 & 15.000 & 15.000 \\
\hline 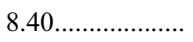 & 15.000 & 15.000 & 15.000 & 15.000 & 15.000 & 15.000 & 15.000 & 15.000 & 15.000 & 15.000 & 15.000 & 15.000 & 15.000 & 15.000 \\
\hline $8.50 \ldots \ldots \ldots \ldots \ldots \ldots \ldots$ & 15.000 & 15.000 & 15.000 & 15.000 & 15.000 & 15.000 & 15.000 & 15.000 & 15.000 & 15.000 & 15.000 & 15.000 & 15.000 & 15.000 \\
\hline $8.60 \ldots \ldots \ldots \ldots \ldots \ldots$ & 15.000 & 15.000 & 15.000 & 15.000 & 15.000 & 15.000 & 15.000 & 15.000 & 15.000 & 15.000 & 15.000 & 15.000 & 15.000 & 15.000 \\
\hline $8.70 \ldots \ldots \ldots \ldots \ldots \ldots$ & 15.000 & 15.000 & 15.000 & 15.000 & 15.000 & 15.000 & 15.000 & 15.000 & 15.000 & 15.000 & 15.000 & 15.000 & 15.000 & 15.000 \\
\hline $8.80 \ldots \ldots \ldots \ldots \ldots \ldots$ & 15.000 & 15.000 & 15.000 & 15.000 & 15.000 & 15.000 & 15.000 & 15.000 & 15.000 & 15.000 & 15.000 & 15.000 & 15.000 & 15.000 \\
\hline $8.90 \ldots \ldots \ldots \ldots \ldots \ldots$ & 15.000 & 15.000 & 15.000 & 15.000 & 15.000 & 15.000 & 15.000 & 15.000 & 15.000 & 15.000 & 15.000 & 15.000 & 15.000 & 15.000 \\
\hline $9.00 \ldots \ldots \ldots \ldots \ldots \ldots$ & 15.000 & 15.000 & 15.000 & 15.000 & 15.000 & 15.000 & 15.000 & 15.000 & 15.000 & 15.000 & 15.000 & 15.000 & 15.000 & 15.000 \\
\hline
\end{tabular}

\begin{tabular}{|c|c|c|c|c|c|c|c|c|c|c|c|c|c|}
\hline $\log (T)$ & $\mathrm{Fe}^{14+}$ & $\mathrm{Fe}^{15+}$ & $\mathrm{Fe}^{16+}$ & $\mathrm{Fe}^{17+}$ & $\mathrm{Fe}^{18+}$ & $\mathrm{Fe}^{19+}$ & $\mathrm{Fe}^{20+}$ & $\mathrm{Fe}^{21+}$ & $\mathrm{Fe}^{22+}$ & $\mathrm{Fe}^{23+}$ & $\mathrm{Fe}^{24+}$ & $\mathrm{Fe}^{25+}$ & $\mathrm{Fe}^{26+}$ \\
\hline $4.00 \ldots \ldots \ldots \ldots \ldots \ldots$ & 15.000 & 15.000 & 15.000 & 15.000 & 15.000 & 15.000 & 15.000 & 15.000 & 15.000 & 15.000 & 15.000 & 15.000 & 15.000 \\
\hline $4.10 \ldots \ldots \ldots \ldots \ldots \ldots$ & 15.000 & 15.000 & 15.000 & 15.000 & 15.000 & 15.000 & 15.000 & 15.000 & 15.000 & 15.000 & 15.000 & 15.000 & 15.000 \\
\hline $4.20 \ldots \ldots \ldots \ldots \ldots \ldots$ & 15.000 & 15.000 & 15.000 & 15.000 & 15.000 & 15.000 & 15.000 & 15.000 & 15.000 & 15.000 & 15.000 & 15.000 & 15.000 \\
\hline $4.30 \ldots \ldots \ldots \ldots \ldots \ldots$ & 15.000 & 15.000 & 15.000 & 15.000 & 15.000 & 15.000 & 15.000 & 15.000 & 15.000 & 15.000 & 15.000 & 15.000 & 15.000 \\
\hline $4.40 \ldots \ldots \ldots \ldots \ldots \ldots$ & 15.000 & 15.000 & 15.000 & 15.000 & 15.000 & 15.000 & 15.000 & 15.000 & 15.000 & 15.000 & 15.000 & 15.000 & 15.000 \\
\hline $4.50 \ldots \ldots \ldots \ldots \ldots \ldots \ldots$ & 15.000 & 15.000 & 15.000 & 15.000 & 15.000 & 15.000 & 15.000 & 15.000 & 15.000 & 15.000 & 15.000 & 15.000 & 15.000 \\
\hline $4.60 \ldots \ldots \ldots \ldots \ldots \ldots$ & 15.000 & 15.000 & 15.000 & 15.000 & 15.000 & 15.000 & 15.000 & 15.000 & 15.000 & 15.000 & 15.000 & 15.000 & 15.000 \\
\hline $4.70 \ldots \ldots \ldots \ldots \ldots \ldots \ldots$ & 15.000 & 15.000 & 15.000 & 15.000 & 15.000 & 15.000 & 15.000 & 15.000 & 15.000 & 15.000 & 15.000 & 15.000 & 15.000 \\
\hline $4.80 \ldots \ldots \ldots \ldots \ldots \ldots$ & 15.000 & 15.000 & 15.000 & 15.000 & 15.000 & 15.000 & 15.000 & 15.000 & 15.000 & 15.000 & 15.000 & 15.000 & 15.000 \\
\hline $4.90 \ldots \ldots \ldots \ldots \ldots \ldots$ & 15.000 & 15.000 & 15.000 & 15.000 & 15.000 & 15.000 & 15.000 & 15.000 & 15.000 & 15.000 & 15.000 & 15.000 & 15.000 \\
\hline $5.00 \ldots \ldots \ldots \ldots \ldots \ldots$ & 15.000 & 15.000 & 15.000 & 15.000 & 15.000 & 15.000 & 15.000 & 15.000 & 15.000 & 15.000 & 15.000 & 15.000 & 15.000 \\
\hline $5.10 \ldots \ldots \ldots \ldots \ldots \ldots$ & 15.000 & 15.000 & 15.000 & 15.000 & 15.000 & 15.000 & 15.000 & 15.000 & 15.000 & 15.000 & 15.000 & 15.000 & 15.000 \\
\hline
\end{tabular}


TABLE 5-Continued

\begin{tabular}{|c|c|c|c|c|c|c|c|c|c|c|c|c|c|}
\hline $\log (T)$ & $\mathrm{Fe}^{14+}$ & $\mathrm{Fe}^{15+}$ & $\mathrm{Fe}^{16+}$ & $\mathrm{Fe}^{17+}$ & $\mathrm{Fe}^{18+}$ & $\mathrm{Fe}^{19+}$ & $\mathrm{Fe}^{20+}$ & $\mathrm{Fe}^{21+}$ & $\mathrm{Fe}^{22+}$ & $\mathrm{Fe}^{23+}$ & $\mathrm{Fe}^{24+}$ & $\mathrm{Fe}^{25+}$ & $\mathrm{Fe}^{26+}$ \\
\hline $5.20 \ldots$ & 15.000 & 15.000 & 15.000 & 15.000 & 15.000 & 15.000 & 15.000 & 15.000 & 15.000 & 15.000 & 15.000 & 15.000 & 15.000 \\
\hline $5.30 \ldots \ldots \ldots \ldots \ldots \ldots \ldots$ & 15.000 & 15.000 & 15.000 & 15.000 & 15.000 & 15.000 & 15.000 & 15.000 & 15.000 & 15.000 & 15.000 & 15.000 & 15.000 \\
\hline $5.40 \ldots \ldots \ldots \ldots \ldots \ldots \ldots$ & 15.000 & 15.000 & 15.000 & 15.000 & 15.000 & 15.000 & 15.000 & 15.000 & 15.000 & 15.000 & 15.000 & 15.000 & 15.000 \\
\hline 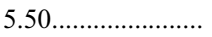 & 15.000 & 15.000 & 15.000 & 15.000 & 15.000 & 15.000 & 15.000 & 15.000 & 15.000 & 15.000 & 15.000 & 15.000 & 15.000 \\
\hline 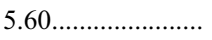 & 15.000 & 15.000 & 15.000 & 15.000 & 15.000 & 15.000 & 15.000 & 15.000 & 15.000 & 15.000 & 15.000 & 15.000 & 15.000 \\
\hline $5.70 \ldots \ldots \ldots \ldots \ldots \ldots \ldots$ & 15.000 & 15.000 & 15.000 & 15.000 & 15.000 & 15.000 & 15.000 & 15.000 & 15.000 & 15.000 & 15.000 & 15.000 & 15.000 \\
\hline $5.80 \ldots \ldots \ldots \ldots \ldots \ldots \ldots$ & 10.923 & 14.448 & 15.000 & 15.000 & 15.000 & 15.000 & 15.000 & 15.000 & 15.000 & 15.000 & 15.000 & 15.000 & 15.000 \\
\hline $5.90 \ldots \ldots \ldots \ldots \ldots \ldots \ldots \ldots \ldots \ldots \ldots$ & 7.281 & 9.903 & 11.983 & 15.000 & 15.000 & 15.000 & 15.000 & 15.000 & 15.000 & 15.000 & 15.000 & 15.000 & 15.000 \\
\hline $6.00 \ldots \ldots \ldots \ldots \ldots \ldots \ldots \ldots \ldots \ldots \ldots \ldots$ & 4.439 & 6.294 & 7.648 & 13.279 & 15.000 & 15.000 & 15.000 & 15.000 & 15.000 & 15.000 & 15.000 & 15.000 & 15.000 \\
\hline $6.10 \ldots \ldots \ldots \ldots \ldots \ldots \ldots \ldots \ldots \ldots$ & 2.421 & 3.621 & 4.431 & 8.719 & 13.687 & 15.000 & 15.000 & 15.000 & 15.000 & 15.000 & 15.000 & 15.000 & 15.000 \\
\hline $6.20 \ldots \ldots \ldots \ldots \ldots \ldots \ldots$ & 1.162 & 1.807 & 2.216 & 5.456 & 9.254 & 13.654 & 15.000 & 15.000 & 15.000 & 15.000 & 15.000 & 15.000 & 15.000 \\
\hline 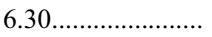 & 0.617 & 0.797 & 0.905 & 3.329 & 6.206 & 9.572 & 13.407 & 15.000 & 15.000 & 15.000 & 15.000 & 15.000 & 15.000 \\
\hline $6.40 \ldots \ldots \ldots \ldots \ldots \ldots \ldots$ & 0.728 & 0.524 & 0.391 & 2.171 & 4.324 & 6.872 & 9.803 & 13.151 & 15.000 & 15.000 & 15.000 & 15.000 & 15.000 \\
\hline $6.50 \ldots \ldots \ldots \ldots \ldots \ldots . . . . . . . . . .$. & 1.084 & 0.565 & 0.226 & 1.487 & 3.062 & 4.960 & 7.171 & 9.730 & 12.556 & 15.000 & 15.000 & 15.000 & 15.000 \\
\hline $6.60 \ldots \ldots \ldots \ldots \ldots \ldots \ldots$ & 1.488 & 0.704 & 0.179 & 1.012 & 2.114 & 3.488 & 5.119 & 7.042 & 9.171 & 11.553 & 14.004 & 15.000 & 15.000 \\
\hline 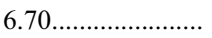 & 1.923 & 0.913 & 0.214 & 0.681 & 1.388 & 2.329 & 3.486 & 4.891 & 6.450 & 8.229 & 10.035 & 15.000 & 15.000 \\
\hline $6.80 \ldots \ldots \ldots \ldots \ldots \ldots \ldots \ldots \ldots \ldots \ldots$ & 2.428 & 1.217 & 0.353 & 0.503 & 0.871 & 1.445 & 2.205 & 3.179 & 4.268 & 5.551 & 6.822 & 14.605 & 15.000 \\
\hline $6.90 \ldots \ldots \ldots \ldots \ldots \ldots . . . . . . . . .$. & 3.075 & 1.682 & 0.657 & 0.527 & 0.598 & 0.856 & 1.276 & 1.884 & 2.578 & 3.445 & 4.271 & 10.485 & 15.000 \\
\hline $7.00 \ldots \ldots \ldots \ldots \ldots . .$. & 3.964 & 2.402 & 1.222 & 0.840 & 0.645 & 0.624 & 0.747 & 1.040 & 1.395 & 1.909 & 2.363 & 7.305 & 12.945 \\
\hline 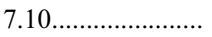 & 5.210 & 3.489 & 2.157 & 1.545 & 1.111 & 0.839 & 0.698 & 0.712 & 0.774 & 0.983 & 1.126 & 5.036 & 9.598 \\
\hline $7.20 \ldots \ldots \ldots \ldots \ldots \ldots \ldots$ & 6.827 & 4.953 & 3.473 & 2.649 & 1.996 & 1.496 & 1.117 & 0.883 & 0.685 & 0.629 & 0.514 & 3.584 & 7.266 \\
\hline 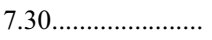 & 8.598 & 6.579 & 4.954 & 3.934 & 3.077 & 2.368 & 1.772 & 1.313 & 0.883 & 0.593 & 0.267 & 2.650 & 5.608 \\
\hline 7.40 ....................... & 10.348 & 8.186 & 6.418 & 5.213 & 4.168 & 3.263 & 2.468 & 1.803 & 1.165 & 0.667 & 0.164 & 1.982 & 4.342 \\
\hline 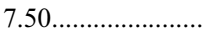 & 12.020 & 9.721 & 7.814 & 6.435 & 5.212 & 4.125 & 3.144 & 2.290 & 1.461 & 0.776 & 0.120 & 1.470 & 3.331 \\
\hline 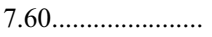 & 13.623 & 11.190 & 9.148 & 7.604 & 6.212 & 4.954 & 3.799 & 2.768 & 1.764 & 0.908 & 0.114 & 1.070 & 2.512 \\
\hline 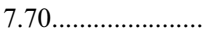 & 15.000 & 12.616 & 10.440 & 8.739 & 7.187 & 5.766 & 4.446 & 3.250 & 2.083 & 1.067 & 0.143 & 0.764 & 1.849 \\
\hline $7.80 \ldots \ldots \ldots \ldots \ldots \ldots \ldots$ & 15.000 & 14.024 & 11.717 & 9.862 & 8.156 & 6.582 & 5.106 & 3.753 & 2.433 & 1.266 & 0.215 & 0.545 & 1.323 \\
\hline $7.90 \ldots \ldots \ldots \ldots \ldots \ldots \ldots \ldots \ldots \ldots \ldots \ldots$ & 15.000 & 15.000 & 13.011 & 11.007 & 9.150 & 7.421 & 5.792 & 4.289 & 2.824 & 1.513 & 0.337 & 0.411 & 0.923 \\
\hline $8.00 \ldots \ldots \ldots \ldots \ldots \ldots \ldots$ & 15.000 & 15.000 & 14.324 & 12.179 & 10.178 & 8.304 & 6.528 & 4.877 & 3.266 & 1.813 & 0.509 & 0.355 & 0.633 \\
\hline $8.10 \ldots \ldots \ldots \ldots \ldots \ldots \ldots$ & 15.000 & 15.000 & 15.000 & 13.349 & 11.211 & 9.198 & 7.283 & 5.493 & 3.745 & 2.154 & 0.723 & 0.362 & 0.432 \\
\hline $8.20 \ldots \ldots \ldots \ldots \ldots \ldots \ldots$ & 15.000 & 15.000 & 15.000 & 14.511 & 12.241 & 10.095 & 8.046 & 6.122 & 4.243 & 2.520 & 0.965 & 0.415 & 0.298 \\
\hline 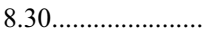 & 15.000 & 15.000 & 15.000 & 15.000 & 13.263 & 10.987 & 8.809 & 6.756 & 4.751 & 2.899 & 1.220 & 0.496 & 0.208 \\
\hline 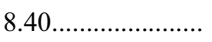 & 15.000 & 15.000 & 15.000 & 15.000 & 14.273 & 11.871 & 9.567 & 7.387 & 5.258 & 3.280 & 1.480 & 0.593 & 0.148 \\
\hline $8.50 \ldots \ldots \ldots \ldots \ldots \ldots \ldots$ & 15.000 & 15.000 & 15.000 & 15.000 & 15.000 & 12.742 & 10.314 & 8.011 & 5.761 & 3.659 & 1.738 & 0.698 & 0.107 \\
\hline 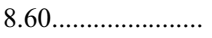 & 15.000 & 15.000 & 15.000 & 15.000 & 15.000 & 13.600 & 11.050 & 8.626 & 6.257 & 4.033 & 1.991 & 0.807 & 0.079 \\
\hline 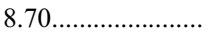 & 15.000 & 15.000 & 15.000 & 15.000 & 15.000 & 14.458 & 11.788 & 9.246 & 6.758 & 4.414 & 2.252 & 0.922 & 0.058 \\
\hline $8.80 \ldots \ldots \ldots \ldots \ldots \ldots \ldots$ & 15.000 & 15.000 & 15.000 & 15.000 & 15.000 & 15.000 & 12.506 & 9.846 & 7.242 & 4.779 & 2.498 & 1.035 & 0.044 \\
\hline $8.90 \ldots \ldots \ldots \ldots \ldots \ldots \ldots$ & 15.000 & 15.000 & 15.000 & 15.000 & 15.000 & 15.000 & 13.208 & 10.431 & 7.713 & 5.132 & 2.735 & 1.144 & 0.033 \\
\hline $9.00 \ldots \ldots \ldots \ldots \ldots \ldots \ldots$ & 15.000 & 15.000 & 15.000 & 15.000 & 15.000 & 15.000 & 13.898 & 11.006 & 8.175 & 5.478 & 2.964 & 1.251 & 0.026 \\
\hline
\end{tabular}

Noте.-Table 5 is available in its entirety in the electronic edition of the Astrophysical Journal Supplement. A portion is shown here for guidance regarding its form and content.

\subsection{First Row Elements}

The differences between our calculated fractional abundances and those of Mazzotta et al. (1998) for $\mathrm{H}$ are negligible. There is no DR process for $\mathrm{H}$, and for the temperature range in Figure 2.1, the difference between the RR rate coefficients of Badnell (2006c) and Mazzotta et al. (1998) is less than $0.2 \%$ (which is better than the accuracy of the published RR rate coefficient fits). For He (Fig. 2.2), we find differences between our calculated fractional abundances and those of Mazzotta et al. to be within 20\% for the neutral and singly ionized ion. Differences in the bare ion are negligible.

\subsection{Second Row Elements}

For Li and Be we find differences between our calculated fractional abundances relative to those of Mazzotta et al. (1998) to be within $20 \%$ for all ionization stages (Figs. 2.3 and 2.4, respectively). The difference for B is also of this order except for the neutral atom, where our calculations give an increase in abundance of $\sim 50 \%$ at a fractional abundance of 0.1 , rising to $\sim 70 \%$ at 0.01 (Fig. 2.5). We attribute this to the $\mathrm{B}^{1+}$ DR rate coefficient calculated by Colgan et al. (2003) being almost an order of mag- nitude larger than that recommended by Mazzotta et al. in the CIE formation zone.

Differences for C (Fig. 2.6) are found to be generally within $20 \%$. Exceptions are at temperatures of $1 \times 10^{4}-2 \times 10^{4} \mathrm{~K}$, where there are differences of up to $40 \%$ (but only for fractional abundances less than 0.1 ), and in the temperature range of $7 \times 10^{4}-$ $2 \times 10^{5} \mathrm{~K}$, where the differences are up to $60 \%$ even at fractional abundances greater than 0.1 .

For $\mathrm{N}$ (Fig. 2.7) we find the largest differences in the neutral and singly charged fractional abundances. These differences are found at temperatures of $1 \times 10^{4}-3 \times 10^{4} \mathrm{~K}$. They rise with decreasing fractional abundance to an $\sim 140 \%$ increase in the neutral abundance and an $\sim 80 \%$ decrease in singly charged abundance at fractional abundances of 0.1 . Outside this temperature range, other ionization stages have differences within $50 \%$. As in the B case, the increase in the neutral abundance and decrease in the singly charged abundance seen in our calculations is due to the $\mathrm{N}^{1+}$ DR rate coefficient of Zatsarinny et al. (2004a) being larger than that of Mazzotta et al. (1998).

For O (Fig. 2.8), the largest differences are found at temperatures of $6 \times 10^{4}-4 \times 10^{5} \mathrm{~K}$. For fractional abundances greater 
TABLE 6

Difference in Peak Fractional Abundance and Temperature between Our AUtostruCtURE-based Calculations and Those of Mazzotta et al. (1998)

\begin{tabular}{|c|c|c|c|}
\hline Ion & $\begin{array}{c}\text { Abundance } \\
\text { Difference } \\
(\%)\end{array}$ & $\begin{array}{c}\text { Temperature } \\
\text { Difference } \\
(\text { dex })\end{array}$ & $\begin{array}{c}\text { Temperature } \\
\text { Difference } \\
(\%)\end{array}$ \\
\hline $\mathrm{F}^{3+} \ldots \ldots \ldots \ldots \ldots \ldots \ldots \ldots$ & -17 & 0.05 & 12 \\
\hline $\mathrm{Mg}^{5+} \ldots \ldots \ldots \ldots \ldots \ldots$ & -24 & -0.02 & -4.5 \\
\hline $\mathrm{Mg}^{6+} \ldots \ldots \ldots \ldots \ldots \ldots$ & 29 & -0.03 & -6.7 \\
\hline $\mathrm{Al}^{2+} \ldots \ldots \ldots \ldots \ldots \ldots$ & -32 & 0.02 & 4.7 \\
\hline $\mathrm{Al}^{6+} \ldots \ldots \ldots \ldots \ldots \ldots \ldots$ & -23 & -0.03 & -6.7 \\
\hline $\mathrm{Al}^{7+} \ldots \ldots \ldots \ldots \ldots \ldots$ & 34 & -0.04 & -8.8 \\
\hline $\mathrm{Al}^{8+} \ldots \ldots \ldots \ldots \ldots \ldots$ & 22 & -0.01 & -2.3 \\
\hline $\mathrm{Si}^{5+} \ldots \ldots \ldots \ldots \ldots \ldots$ & -27 & 0.04 & 9.6 \\
\hline $\mathrm{P}^{8+} \ldots \ldots \ldots \ldots \ldots \ldots$ & -26 & 0.00 & 0.0 \\
\hline $\mathrm{S}^{8+} \ldots \ldots \ldots \ldots \ldots \ldots \ldots$ & -5.2 & 0.05 & 12 \\
\hline 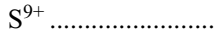 & -42 & 0.02 & 4.7 \\
\hline $\mathrm{Cl}^{8+} \ldots \ldots \ldots \ldots \ldots \ldots$ & -7.2 & 0.05 & 12 \\
\hline $\mathrm{Cl}^{9+} \ldots \ldots \ldots \ldots \ldots \ldots$ & -8.6 & 0.06 & 15 \\
\hline $\mathrm{Cl}^{10+} \ldots \ldots \ldots \ldots \ldots \ldots$ & -47 & 0.03 & 7.2 \\
\hline $\mathrm{K}^{8+} \ldots \ldots \ldots \ldots \ldots \ldots \ldots$ & 36 & 0.02 & 4.7 \\
\hline $\mathrm{K}^{11+} \ldots \ldots \ldots \ldots \ldots \ldots \ldots$ & 22 & 0.06 & 15 \\
\hline $\mathrm{K}^{12+} \ldots \ldots \ldots \ldots \ldots \ldots \ldots$ & -41 & 0.05 & 12 \\
\hline $\mathrm{Ca}^{9+} \ldots \ldots \ldots \ldots \ldots \ldots$ & 48 & 0.03 & 7.2 \\
\hline $\mathrm{Ca}^{11+} \ldots \ldots \ldots \ldots \ldots \ldots$ & 21 & 0.03 & 7.2 \\
\hline $\mathrm{Ca}^{12+} \ldots \ldots \ldots \ldots \ldots$ & 29 & 0.07 & 17 \\
\hline $\mathrm{Ca}^{13+} \ldots \ldots \ldots \ldots \ldots \ldots$ & -40 & 0.06 & 15 \\
\hline $\mathrm{Ca}^{14+} \ldots \ldots \ldots \ldots \ldots \ldots$ & -24 & 0.04 & 9.6 \\
\hline $\mathrm{Sc}^{10+} \ldots \ldots \ldots \ldots \ldots \ldots$ & 57 & 0.03 & 7.2 \\
\hline $\mathrm{Sc}^{14+} \ldots \ldots \ldots \ldots \ldots \ldots$ & -22 & 0.02 & 4.7 \\
\hline $\mathrm{Ti}^{15+} \ldots \ldots \ldots \ldots \ldots \ldots \ldots \ldots$ & -21 & 0.03 & 7.2 \\
\hline $\mathrm{V}^{12+} \ldots \ldots \ldots \ldots \ldots \ldots$ & 25 & 0.01 & 2.3 \\
\hline $\mathrm{Mn}^{16+} \ldots \ldots \ldots \ldots \ldots$ & 22 & 0.02 & 4.7 \\
\hline $\mathrm{Mn}^{20+} \ldots \ldots \ldots \ldots \ldots \ldots$ & -21 & 0.02 & 4.7 \\
\hline $\mathrm{Fe}^{18+} \ldots \ldots \ldots \ldots \ldots$ & 28 & 0.03 & 7.2 \\
\hline $\mathrm{Fe}^{19+} \ldots \ldots \ldots \ldots \ldots \ldots \ldots \ldots \ldots \ldots \ldots \ldots$ & -26 & 0.03 & 9.6 \\
\hline 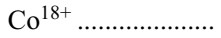 & 28 & 0.03 & 7.2 \\
\hline $\mathrm{Co}^{19+} \ldots \ldots \ldots \ldots \ldots \ldots$ & 48 & 0.05 & 12 \\
\hline 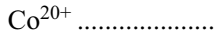 & -37 & 0.05 & 12 \\
\hline $\mathrm{Co}^{21+} \ldots \ldots \ldots \ldots \ldots \ldots$ & -21 & 0.04 & 9.6 \\
\hline $\mathrm{Co}^{22+} \ldots \ldots \ldots \ldots \ldots$ & -26 & 0.02 & 4.7 \\
\hline 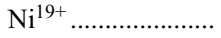 & 34 & 0.04 & 9.6 \\
\hline $\mathrm{Ni}^{20+} \ldots \ldots \ldots \ldots \ldots \ldots$ & 61 & 0.06 & 15 \\
\hline 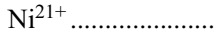 & -42 & 0.07 & 17 \\
\hline 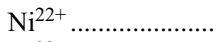 & -25 & 0.05 & 12 \\
\hline $\mathrm{Ni}^{23+} \ldots \ldots \ldots \ldots \ldots \ldots$ & -24 & 0.04 & 9.6 \\
\hline
\end{tabular}

Notes. - We list here ions showing a difference that is $>20 \%$ between peak fractional abundance from our calculations and those of Mazzotta et al. (1998) or have a difference in peak formation temperature that is $\geq 0.05$ in the dex. For each ion we list the percentage change compared to the Mazzotta et al. (1998) results, with positive values indicating an increase and negative indicating a decrease. Also listed is the change in the dex and the percentage change of the temperature at which the fractional abundance peaks.

than 0.1 , the difference is as large as a $40 \%$ decrease for the singly charged ion. The difference is within $30 \%$ for the other ions. When fractional abundances as low as 0.01 are considered, the decrease in the singly charged abundance is up to $60 \%$.

Of all the second row elements, F (Fig. 2.9) shows the largest deviation from the Mazzotta et al. (1998) results. This difference is most pronounced for the first four ionization stages. In particular, at temperatures of $1 \times 10^{4}-3 \times 10^{4} \mathrm{~K}$ we find differences up to $120 \%$ for fractional abundances from 0.1 to 0.01 . Also for these four ions, at temperatures of $7 \times 10^{4}-3 \times 10^{5} \mathrm{~K}$ the differences are $\sim 200 \%$ for fractional abundances down to 0.1 , and nearly $300 \%$ for abundances down to 0.01 .
$\mathrm{Ne}$ (Fig. 2.10) shows differences of up to $100 \%$ at fractional abundances of 0.1 . The largest of these is in the temperature range $1 \times 10^{5}-4 \times 10^{5} \mathrm{~K}$, where the $\mathrm{Ne}^{3+}$ abundance is decreased relative to the Mazzotta et al. (1998) results and the $\mathrm{Ne}^{4+}$ abundance is increased.

\subsection{Third Row Elements}

We find relatively small differences for $\mathrm{Na}$ (less than $30 \%$ ), except for $\mathrm{Na}^{3+}, \mathrm{Na}^{4+}$, and $\mathrm{Na}^{5+}$ at temperatures of $2 \times 10^{5}-7 \times$ $10^{5} \mathrm{~K}$ (Fig. 2.11). In this temperature range for $\mathrm{Na}^{3+}$ we find a decrease of $\sim 120 \%$ in the fractional abundance at 0.1 and $\sim 200 \%$ in the fractional abundance at 0.01 . For $\mathrm{Na}^{4+}$ and $\mathrm{Na}^{5+}$, increases of $\sim 60 \%$ are seen at a fractional abundance of 0.1 .

The largest differences in $\mathrm{Mg}$ peak abundance (Fig. 2.12) are for $\mathrm{Mg}^{5+}$, which shows a $24 \%$ decrease relative to Mazzotta et al. (1998), and $\mathrm{Mg}^{6+}$, which shows a $29 \%$ increase. Off peak, the largest difference for $\mathrm{Mg}$ is in the neutral atom. At $1 \times 10^{4}-2 \times$ $10^{4} \mathrm{~K}$, for fractional abundances between 0.01 and 0.4 , our results are larger then those of Mazzotta et al. (1998) by between $160 \%$ and $250 \%$. This is due to the $\mathrm{Mg}^{1+} \mathrm{DR}$ and RR rate coefficients of Altun et al. (2006) and Badnell (2006b), respectively, being around a factor of 2 larger than those recommended by Mazzotta et al. (1998). Other differences for $\mathrm{Mg}$ are concentrated around the $3 \times 10^{5}-2 \times 10^{6} \mathrm{~K}$ temperature range, where they are up to $100 \%$.

Differences in our fractional abundance curves relative to those of Mazzotta et al. (1998) for Al (Fig. 2.13) are seen across a wide range of ionization stages. $\mathrm{Al}^{2+}$ shows a $32 \%$ decrease in peak abundance, $\mathrm{Al}^{6+}$ shows a $23 \%$ decrease, $\mathrm{Al}^{7+}$ shows a $34 \%$ increase, and $\mathrm{Al}^{8+}$ shows a $22 \%$ increase. At a fractional abundance of 0.1 , the maximum difference is $\sim 150 \%$ for all ions.

For Si (Fig. 2.14), the peak abundance of $\mathrm{Si}^{5+}$ is decreased by $27 \%$. The differences seen for $\mathrm{Si}$ are up to $70 \%$ relative to Mazzotta et al. (1998) for all but the F- and Ne-like ions. These two ions show differences of over $200 \%$ at fractional abundances of 0.1 and temperatures between $2 \times 10^{5}$ and $6 \times 10^{5} \mathrm{~K}$.

The largest difference in peak abundance for P (Fig. 2.15) is $\mathrm{P}^{8+}$, which shows a $26 \%$ decrease relative to the results of Mazzotta et al. (1998). Other differences in abundance between our results and Mazzotta et al. (1998) for P are largest at $3 \times$ $10^{5}-3 \times 10^{6} \mathrm{~K}$. In particular, $\mathrm{P}^{5+}$ shows an increase of $\sim 140 \%$ at a fractional abundance of 0.1 , and of $\sim 250 \%$ at an abundance of 0.01 .

$\mathrm{S}, \mathrm{Cl}$, and Ar (Figs. 2.16, 2.17, and 2.18, respectively) show the greatest peak abundance difference in the $\mathrm{N}$-like ion. The decrease for $\mathrm{S}^{9+}$ is $42 \%$ relative to the fractional abundance of Mazzotta et al. (1998), for $\mathrm{Cl}^{10+}$ it is $47 \%$, and for $\mathrm{Ar}^{11+}$ it is $14 \%$. Also, the temperature of peak formation of $\mathrm{Cl}^{9+}$ is increased by 0.06 in the dex. These three elements all show maximum discrepancy in the temperature range $6 \times 10^{5}-3 \times 10^{6} \mathrm{~K}$. For $\mathrm{S}$ these differences are up to a factor of 3 at fractional abundances of 0.1 , and up to a factor of 6 at fractional abundances of 0.01 . For $\mathrm{Cl}$ these differences are up to a factor of 4.2 at fractional abundances of 0.1 , and up to a factor of 11 at fractional abundances of 0.01 . For Ar these differences are no greater than a factor of 1.5 for fractional abundances of 0.1 and up to a factor of 2 at fractional abundances of 0.01 .

Figure 3.1 shows the differences in fractional abundances calculated using the data of Badnell (2006a, 2006b) compared to the data of $\mathrm{Gu}(2003 \mathrm{~b}, 2003 \mathrm{a}, 2004)$ for $\mathrm{Mg}$. These differences are up to $30 \%$ for fractional abundances of 0.1 and greater, and up to $50 \%$ for fractional abundances of 0.01 . They are concentrated in temperature regions of $1 \times 10^{4}-2 \times 10^{4}$ and $3 \times 10^{5}-2 \times$ $10^{6} \mathrm{~K}$. Comparison with the calculated abundances of Si ( Fig. 3.2) shows differences up to $25 \%$ at fractional abundances of 0.1 , 
rising to $\sim 30 \%$ at abundances of 0.01 . S and $\mathrm{Ar}$ abundances were also calculated using the data of Gu. Agreement here for S (Fig. 3.3) is within 25\% at an abundance of 0.1 and $40 \%$ at an abundance of 0.01. For Ar (Fig. 3.4), the agreement is within $20 \%$ at an abundance of 0.1 and $30 \%$ at an abundance of 0.01 . For $\mathrm{S}$ and Ar, the largest difference is seen for the $\mathrm{Ne}-$ and Mg-like ions.

\subsection{Fourth Row Elements}

For K and Ca (Figs. 2.19 and 2.20, respectively), the largest peak abundance differences are for the Na-, O-, and N-like ions. For Na-like $\mathrm{K}^{8+}$ the increase is $36 \%$ relative to Mazzotta et al. (1998), and for $\mathrm{Ca}^{9+}$ it is $48 \%$. For O-like $\mathrm{K}^{11+}$ the increase is $22 \%$, and for $\mathrm{Ca}^{12+}$ it is $29 \%$. For N-like $\mathrm{K}^{12+}$ the decrease is $41 \%$ relative to Mazzotta et al. (1998), and for $\mathrm{Ca}^{13+}$ it is $40 \%$. Large increases in the temperature of peak abundance are found for $\mathrm{K}^{11+}, \mathrm{Ca}^{12+}$ and $\mathrm{Ca}^{13+}$; they are 0.06, 0.07, and 0.06 in the dex, respectively. For these elements the largest fractional abundance differences are seen between $2 \times 10^{6}$ and $6 \times 10^{6} \mathrm{~K}$ and are within a factor of 5 at fractional abundances of 0.1 and up to a factor of 8 at fractional abundances of 0.01 .

Differences between our results and those of Mazzotta et al. (1998) for Sc (Fig. 2.21) at peak abundance are a 57\% increase for $\mathrm{Sc}^{10+}$ and a $21 \%$ decrease for $\mathrm{Sc}^{14+}$. Differences for all ions are up to $80 \%$ at fractional abundances of 0.1 , and $150 \%$ for fractional abundances of 0.01 . The largest differences are between $7 \times 10^{5}$ and $1 \times 10^{7} \mathrm{~K}$.

The largest Ti and V peak abundance differences (Figs. 2.22 and 2.23 , respectively) are a $21 \%$ decrease for $\mathrm{Ti}^{15+}$ and a $25 \%$ increase for $\mathrm{V}^{12+}$. These elements show differences in fractional abundance from our calculations relative to those of Mazzotta et al. (1998) concentrated at temperatures of $3 \times 10^{6}-1 \times 10^{7} \mathrm{~K}$. These differences are less than a factor of 2 for fractional abundances of 0.1 and above. They are up to a factor of 3 at fractional abundances of 0.01 .

$\mathrm{Cr}, \mathrm{Mn}$, and Fe (Figs. 2.24, 2.25, and 2.26, respectively) all show similar differences relative to the Mazzotta et al. (1998) data. Of these elements, the largest percentage difference in peak abundance is seen for the $\mathrm{Fe}^{18+}$ ion, which has an increase of $28 \%$. Other differences for these three elements are in the temperature range $4 \times 10^{6}-2 \times 10^{7} \mathrm{~K}$ and are up to a factor of 2.2 at fractional abundances of 0.1 and a factor of 3 at fractional abundances of 0.01 .

Co and Ni (Figs. 2.27 and 2.28, respectively) have a number of ions with large differences in peak fractional abundances relative to Mazzotta et al. (1998). For Co, the largest of these are $\mathrm{Co}^{19+}$, which has a $48 \%$ increase in peak abundance, and $\mathrm{Co}^{20+}$, which has a $37 \%$ decrease. The temperature of peak formation is also increased by 0.05 in the dex in both cases. The largest peak abundance differences for $\mathrm{Ni}$ are for $\mathrm{Ni}^{19+}, \mathrm{Ni}^{20+}$, and $\mathrm{Ni}^{21+}$, with a $34 \%$ increase, a $61 \%$ increase, and a $42 \%$ decrease, respectively. $\mathrm{Ni}^{20+}$ and $\mathrm{Ni}^{21+}$ also have an increase in peak abundance temperature of 0.06 and 0.07 in the dex, respectively. Both Co and $\mathrm{Ni}$ show the largest discrepancies between our results and those of Mazzotta et al. (1998) between $7 \times 10^{6}$ and $2 \times 10^{7} \mathrm{~K}$. For Co these differences are up to a factor of 3.5 at fractional abundances of 0.1 and up to a factor of 4 at fractional abundances of 0.01 . For $\mathrm{Ni}$ they are up to a factor of 4 at fractional abundances of 0.1 and up to a factor of 7 at fractional abundances of 0.01 .

In Figures 2.29 and 2.30 we present the ionization fractional abundances of $\mathrm{Cu}$ and $\mathrm{Zn}$ without comparison. We note that Mazzitelli \& Mattioli (2002) present fractional abundance results for these elements using updated ionization rate coefficients, but the purpose of our present work is to highlight the effect of im- proved recombination data. Comparison to Mazzitelli \& Mattioli (2002) will be considered in a future work where we include updated EII data.

Comparing with $\mathrm{Ca}$ abundances from the data of $\mathrm{Gu}$ (2003b, $2003 a, 2004)$ gives differences not larger than $20 \%$ at fractional abundances of 0.1 and not larger than $30 \%$ at fractional abundances of 0.01 for all temperatures covered here (Fig. 3.5). Comparing for $\mathrm{Fe}$ gives differences in the fractional abundance that are within $20 \%$ at all temperatures (Fig. 3.6). For Ni, differences in the fractional abundance are within $15 \%$ at fractional abundances of 0.1 and $25 \%$ at fractional abundances of 0.01 (Fig. 3.7).

\section{CONCLUSION}

This work has collected the most recent state-of-the-art theoretical DR and RR rate coefficients and, based on these data, calculated new CIE ionic fractional abundances of all elements from $\mathrm{H}$ to $\mathrm{Zn}$. For these elements we have implemented the data of Badnell (2006a, 2006b) for all charge states from bare through Na-like. DR data for $\mathrm{Mg}, \mathrm{Si}, \mathrm{S}, \mathrm{Ar}, \mathrm{Ca}, \mathrm{Fe}$, and $\mathrm{Ni}$ have also been calculated by $\mathrm{Gu}(2003 \mathrm{~b}, 2004)$ for all charge states from $\mathrm{H}$ through Na-like. In addition, RR data for these seven elements has been calculated by $\mathrm{Gu}$ (2003a) for all charge states from bare through F-like. We have also computed ionization balance results using these data of $\mathrm{Gu}$. For ionization stages not provided by the above calculations, we revert to the recombination data recommended by Mazzotta et al. (1998) for all elements up to and including $\mathrm{Ni}$, and those recommended by P. Mazzotta (2000, private communication) for $\mathrm{Cu}$ and $\mathrm{Zn}$. We also use the EII data from these two sources.

Our results represent a significant improvement over past CIE calculations. This will impact directly on the plasma conditions inferred from spectral observations and is thus of much importance for the astrophysics community. We will further this study in subsequent work by the inclusion of experimentally derived DR data for singly and doubly charged ions (where available), incorporating CT, and updating the EII data to the extent possible.

We conclude by noting that further progress in CIE calculations will require a concerted theoretical and experimental effort to generate the remaining needed atomic data. Modern DR and RR data are urgently needed for ions with 12 or more bound electrons. There is also a need for improved EII and CT data. There has been no significant revision or laboratory benchmarking of the recommended EII database since around 1990. In addition, the latest compilation of recommended CT rate coefficients dates back to Kingdon \& Ferland (1996). This is in need of updating to reflect advances in $\mathrm{CT}$ in the last decade. We propose that all future data for DR, RR, CT, and EII should be generated aiming for an accuracy of better than $35 \%$. This will match the accuracy of the modern electron-ion recombination measurements and calculations and help to ensure a uniformity of accuracy for future CIE calculations. Such an accurate and up-to-date database is crucial for being able to produce reliable CIE calculations for the astrophysics community.

We thank M. Bannister, M. Finkenthal, T. Kato, E. Landi, S. Loch, M. Mattioli, P. Mazzotta, and R. Smith for stimulating conversations. P. B., T. W. G., W. M., and D. W. S. were supported in part by the NASA Solar and Heliospheric Physics Supporting Research and Technology program and the NASA Astronomy and Physics Research and Analysis Program. N. R. B. was supported in part by PPARC PPA $\backslash G \backslash S 2003 \backslash 00055$. J. M. L. was supported by NASA LWS Contract NNH05AAOSI and by Basic Research Funds of the Office of Naval Research. 


\section{REFERENCES}

Altun, Z., Yumak, A., Badnell, N. R., Colgan, J., \& Pindzola, M. S. 2004, A\&A, 420, 775 (erratum 433, 395 [2005])

Altun, Z., Yumak, A., Badnell, N. R., Loch, S. D., \& Pindzola, M. S. 2006, A\&A, 447, 1165

Arnaud, M., \& Raymond, J. C. 1992, ApJ, 398, 394

Arnaud, M., \& Rothenflug, R. 1985, A\&AS, 60, 425

Badnell, N. R. 1986, J. Phys. B, 19, 3827 2006a, Atomic and Molecular Diagnostic Processes in Plasmas (Dept. Physics, Univ. Strathclyde), http://amdpp.phys.strath.ac.uk/tamoc/DR/ 2006b, Atomic and Molecular Diagnostic Processes in Plasmas (Dept.

Physics, Univ. Strathclyde), http://amdpp.phys.strath.ac.uk/tamoc/RR/ 2006c, A\&A, 447, 389

2006d, ApJS, submitted (astro-ph/0604144)

Badnell, N. R., et al. 2003, A\&A, 406, 1151

Bautista, M. A., \& Badnell, N. R. 2006, A\&A, submitted

Beiersdorfer, P. 2003, ARA\&A, 41, 343

Bell, K. L., Gilbody, H. B., Hughes, J. G., Kingston, A. E., \& Smith, F. J. 1983 J. Phys. Chem. Ref. Data, 12, 891

Colgan, J., Pindzola, M. S., \& Badnell, N. R. 2004, A\&A, 417, 1183 (erratum 429, 369 [2005])

Colgan, J., Pindzola, M. S., Whiteford, A. D., \& Badnell, N. R. 2003, A\&A, 412, 597

DeWitt, D. R., Schuch, R., Gao, H., Asp., S., Biedermann, C., Chen, M. H., \& Badnell, N. R. 1996, Phys. Rev. A, 53, 2327

Fogle, M., Badnell, N. R., Eklöw, N., Mohamed, T., \& Schuch, R. 2003, A\&A 409, 781

Fogle, M., Badnell, N. R., Glans, P., Loch, S. D., Madzunkov, S., Abdel-Naby, Sh., A., Pinidzola, M. S., \& Schuch, R. 2005, A\&A, 442, 757

Gorczyca, T. W., \& Badnell, N. R. 1997, Phys. Rev. Lett., 79, 2783

Gorczyca, T. W., Kodituwakka, C. N., Korista, K. T. Zatsarinny, O., Badnell, N. R., Behar, E., Chen, M. H., \& Savin, D. W. 2003, ApJ, 592, 636

Gu, M. F. 2003a, ApJ, 589, 1085

. 2003b, ApJ, 590, 1131

2004, ApJS, 153, 389

Higgins, M. J., et al. 1989, Culham Lab. Rep. CLM-R 294

Kaastra, J. S., \& Mewe, R. 1993, A\&AS, 97, 443

Kato, T., Masai, K., \& Arnaud, M. 1991, National Institute for Fusion Science NIFS-DATA-14

Kingdon, J. B., \& Ferland, G. J. 1996, ApJS, 106, 205

Landi, M., \& Monsignori Fossi, B. C. 1991, A\&AS, 91, 183

Lennon, M. A., Bell, K. L., Gilbody, H. B., Hughes, J. G., Kingston, A. E. Murray, M. J., \& Smith, F. J. 1988, J. Phys. Chem. Ref. Data, 17, 1285

Linkemann, J., Müller, A., Kenntner, J., Habs, D., Schwalm, D., Wolf, A., Badnell, N. R., \& Pindzola, M. S. 1995, Phys. Rev. Lett., 74, 4173

Loch, S. D., Ludlow, J. A., Pindzola, M. S., Whiteford, A. D., \& Griffin, D., C. 2005, Phys. Rev. A, 72, 2716
Lotz, W. 1968, Z. Phys., 216, 241

Masai, K. 1997, A\&A, 324, 410

Mazzitelli, G., \& Mattioli, M. 2002, At. Data Nucl. Data Tables, 82, 313

Mazzotta, P., Mazzitelli, G., Colafrancesco, S., \& Vittorio, N. 1998, A\&AS, 133,403

Mitnik, D. M., \& Badnell, N. R. 2004, A\&A, 425, 1153

Müller, A. 1995, in Atomic and Plasma-Material Interaction Data for Fusion, Suppl. to Nucl. Fusion, Vol. 6 (Vienna: IAEA), 59 1999, Int. J. Mass Spectr., 192, 9

Müller, A., \& Wolf, A. 1997, in Accelerator-based Atomic Physics Techniques and Applications, ed. S. M. Shafroth \& J. C. Austin (New York: AIP), 147

Nahar, S., N. 1999, ApJS, 120, 131 2005a, ApJS, 156, 93 2005b, ApJS, 158, 80 2006, ApJS, 164, 280

Nahar, S., N., \& Pradhan, A., K. 1997, ApJS, 111, 339 2003, ApJS, 149, 239 2006, ApJS, 162, 417

Nahar, S., N., Pradhan, A. K., \& Zhang, H. L. 2000, ApJS, 131, 375 2001, ApJS, 133, 255

Nussbaumer, H., \& Storey, P. J. 1983, A\&A, 126, 75

Pindzola, M. S., Badnell, N. R., \& Griffin, D. C. 1992, Phys. Rev. A, 46, 5725

Pindzola, M. S., \& Buie, M. J. 1988, Phys. Rev. A, 37, 3232

Pindzola, M. S., Griffin, D. C., Bottcher, C., Younger, S. M., \& Hunter, H. T. 1987, Nucl. Fusion, Special Supp., 21

Pradhan, A. K., Chen, G., X., Nahar, S. N., \& Zhang, H., L. 2001, Phys. Rev. Lett., 87, 183201

Savin, D. W., \& Laming, J. M. 2002, ApJ, 566, 1166

Savin, D. W., et al. 1997, ApJ, 489, L115 1999, ApJS, 123, 687 2003, ApJS, 147, 421 2006, ApJ, 642, 1275

Schippers, S. 1999, Phys. Scr., 80, 158

Seaton, M. J., \& Storey, P. J. 1976, Atomic Processes and Applications, ed. P. G. Burke \& B. L. Moiseiwitsch (Amsterdam: North Holland), 133

Shull, J. M., \& van Steenberg, M. 1982, ApJS, 48, 95 (erratum 49, 351)

Verner, D. A., \& Ferland, G. J. 1996, ApJS, 103, 467

Zatsarinny, O., Gorczyca, T. W., Fu, J., Korista, K. T., Badnell, N. R., \& Savin, D. W. 2006, A\&A, 447, 379

Zatsarinny, O., Gorczyca, T. W., Korista, K. T., Badnell, N. R., \& Savin, D. W.

2003, A\&A, 412, 587 (erratum 438, 743 [2005]) 2004a, A\&A, 417, 1173 (erratum 440, 1203 [2005]) 2004b, A\&A, 426, 699 